\title{
Thermodynamic properties of 1-naphthol: Mutual validation of experimental and computational results ${ }^{*}$
}

\author{
Robert D. Chirico, ${ }^{a}{ }^{\dagger}$ William V. Steele ${ }^{b}$ Andrei F. Kazakov, ${ }^{a}$
}

${ }^{a}$ Applied Chemicals and Materials Division

National Institute of Standards and Technology

Boulder, CO 80305-3337, U.S.A.

${ }^{b}$ Physical Properties Research Facility

Chemical and Biomolecular Engineering Department

University of Tennessee

Knoxville, TN 37996-2200, U.S.A.

\footnotetext{
* Contribution of the National Institute of Standards and Technology, not subject to copyright in the United States.

† Corresponding author. E-mail address: robert.chirico@nist.gov 


\begin{abstract}
Thermodynamic properties for 1-naphthol (Chemical Abstracts registry number [90-153]) in the ideal-gas state are reported based on both experimental and computational methods. Measured properties included the triple-point temperature, enthalpy of fusion, and heat capacities for the crystal and liquid phases by adiabatic calorimetry; vapor pressures by inclined-piston manometry and comparative ebulliometry; and the enthalpy of combustion of the crystal phase by oxygen bomb calorimetry. Critical properties were estimated. Entropies for the ideal-gas state were derived from the experimental studies for the temperature range $298.15 \leq T / \mathrm{K} \leq 600$, and independent statistical calculations were performed based on molecular geometry optimization and vibrational frequencies calculated at the B3LYP/6-31+G(d,p) level of theory. The mutual validation of the independent experimental and computed results is achieved with a scaling factor of 0.975 applied to the calculated vibrational frequencies. This same scaling factor was successfully applied in the analysis of results for other polycyclic molecules, as described in a series of recent articles by this research group. This article reports the first extension of this approach to a hydroxy-aromatic compound. All experimental results are compared with property values reported in the literature. Thermodynamic consistency between properties is used to show that several studies in the literature are erroneous. The enthalpy of combustion for 1-naphthol was also measured in this research, and excellent agreement is seen with several values already reported in the literature.
\end{abstract}


Keywords: 1-naphthol; computational chemistry; enthalpy of combustion, enthalpy of formation; enthalpy of fusion; heat capacity; ideal-gas properties; sublimation pressure; triple point temperature; vapor pressure 


\section{Introduction}

The present article is part of a series in which we report studies of experimental and computed thermodynamic properties for aromatic ring systems. Previous work has included an extensive series of azaaromatics (2-methylquinoline [1], 8-methylquinoline [1], 2,6-dimethylquinoline [1], phenazine [2], acridine [2], phenanthridine [3], 1,10phenanthroline [3], and 7,8-benzoquinoline [3]), 1-phenyl and 2-phenylnaphthalene [4], and 9-fluorenone [5]. All studies included calculations performed at the B3LYP/6$31+\mathrm{G}(\mathrm{d}, \mathrm{p})$ model chemistry with a consistent scaling factor (0.975), with excellent accord demonstrated between computed entropies for the ideal gas and those based on the experimental property measurements. In the present work, this approach is applied for the first time to a hydroxyl-aromatic compound, 1-naphthol (Chemical Abstracts Service Registry Number [90-15-3]).

As we have noted previously [2], the rigid nature of fused-ring systems makes such molecules good candidates for accurate computation of thermodynamic properties for the ideal-gas state with statistical methods. In the present paper, entropies for the idealgas state are derived from the reported thermodynamic property measurements and are compared with independently calculated values derived with the methods of computational chemistry. The accord achieved provides a mutual validation of the two methods, and demonstrates a path to the quantification of uncertainties for the computational methods. Derivation of ideal-gas properties from computational methods with reliable uncertainties provides essential data that are, otherwise, impractical or impossible to obtain, such as those for toxic, unstable, or prohibitively expensive materials. Applications of ideal-gas properties in thermodynamics include key roles in 
property predictions, consistency analyses, constrained property equations, and equation of state formulations.

Here, we report thermodynamic properties of 1-naphthol measured with adiabatic heat-capacity calorimetry, comparative ebulliometry, inclined-piston gauge manometry, and oxygen bomb calorimetry. Standard molar enthalpies, entropies, enthalpies of formation, entropies of formation, and Gibbs energies of formation for the ideal gas state were derived based on the experimental studies. Entropies for the ideal gas state were computed independently at the B3LYP/6-31+G(d,p) model chemistry with the same scaling factor used in previous work [1-5]. Excellent accord between the computed and experimental entropies is demonstrated. Measured and derived thermodynamic property values are compared with those reported in the literature, where several studies are demonstrated to be of low quality. A summary of the new experimental thermodynamic property measurements reported here is given in table 1.

\section{Experimental}

\subsection{Materials}

The research group of Professor E. J. "Pete" Eisenbraun (retired) of Oklahoma State University purified the sample of 1-naphthol used in this research. A commercial sample was Soxhlet extracted through neutral alumina with hexane, followed by reaction with picric acid in hot methanol. The resulting picrate was triply recrystallized from methanol, filtered, and dried. The picrate was cleaved with basic alumina by Soxhlet extraction with ethyl ether. A mixture of hexanes was added, and the resulting crystals were filtered and dried by evacuation at room temperature. 
The mole fraction purity $x$ of the sample $(x=0.9990)$ was determined by fractional melting as part of the adiabatic calorimetric studies. Sample handling during purification and transfer was done under a dry atmosphere of argon, nitrogen, or helium, or by vacuum distillation. Purification of the water and decane used as reference materials in the ebulliometric vapor-pressure measurements has been described [6].

\subsection{Physical constants and standards}

Property values for 1-naphthol are reported in terms of molar mass $M=$ $144.17 \mathrm{~g} \cdot \mathrm{mol}^{-1}$ [7] based on the formula $\mathrm{C}_{10} \mathrm{H}_{8} \mathrm{O}$ and the gas constant $R=8.3144621 \mathrm{~J} \cdot \mathrm{K}^{-1} \cdot \mathrm{mol}^{-1}$ adopted in 2010 by CODATA [8]. Platinum resistance thermometers used in these measurements were calibrated by comparison with standard thermometers calibrated at the National Bureau of Standards (NBS), now the National Institute of Standards and Technology (NIST). All temperatures were measured in terms of IPTS-68 [9] and were converted to ITS-90 with published scale differences [10]. The thermometer used in the adiabatic heat-capacity study was calibrated below $T / \mathrm{K}=13.81$ with the method of McCrackin and Chang [11]. Mass, time, electrical resistance, and potential difference were measured in terms of standards traceable to calibrations at NIST.

\subsection{Adiabatic calorimetry}

Heat-capacities, enthalpy increments, and the triple-point temperature for 1-naphthol were measured with an adiabatic calorimetric system described previously [12]. Sample container characteristics and sealing conditions are given in table 2. Energies were measured with a relative standard uncertainty of 0.01 percent. Temperatures were measured with a repeatability of $0.0001 \mathrm{~K}$, which represents the lower limit in the 
standard uncertainty for measured temperature increments. The standard uncertainty for a single temperature measurement was $0.005 \mathrm{~K}$, due to uncertainties associated with the thermometer calibration, and represents the lower limit for the standard uncertainty in reported absolute temperatures, including phase-transition temperatures. The energy increments to the filled platinum calorimeter were corrected for enthalpy changes in the empty calorimeter, for the helium exchange gas, and for vaporization of the sample into the free space of the sealed vessel. The maximum correction to the measured energy for the helium exchange gas was 0.25 percent near $T / K=4.9$, and the sizes of the other two adjustments are given in table 2 .

\subsection{Vapor pressure apparatus}

The ebulliometric equipment and procedures for determination of the vapor pressures have been described [13]. Matching ebulliometers were used to reflux the 1-naphthol and a standard of known vapor pressure (water or decane) under a common atmosphere of $\mathrm{He}(\mathrm{g})$. The boiling and condensation temperatures were determined for both substances, and the vapor pressure of 1-naphthol was derived from the condensation temperature of the standard. In the pressure range $25 \mathrm{kPa}$ to $270 \mathrm{kPa}$, water was used as the standard, and the pressures were derived from the international equation of state for ordinary water [14]. For the range $2 \mathrm{kPa}$ to $25 \mathrm{kPa}$, decane was used as the standard. Vapor pressures for decane were calculated with equation 1 of reference 6.

The standard uncertainty for the temperature measurements in the ebulliometric vapor-pressure studies was $0.002 \mathrm{~K}$. Standard uncertainties in the pressures $u(p)$ were calculated with the expression:

$$
u(p)=(0.002 \mathrm{~K})\left\{\left(\mathrm{d} p_{\text {ref }} / \mathrm{d} T\right)^{2}+\left(\mathrm{d} p_{\mathrm{x}} / \mathrm{d} T\right)^{2}\right\}^{1 / 2},
$$


where $p_{\text {ref }}$ is the vapor pressure of the reference substance and $p_{\mathrm{x}}$ is the vapor pressure of the sample under study. The repeatability of the temperature measurements was $5 \cdot 10^{-4} \mathrm{~K}$

Vapor pressures for 1-naphthol were measured with an inclined-piston apparatus described initially by Douslin and McCullough [15] and Douslin and Osborn [16]. Subsequent changes to the equipment and procedures were reported [6]. Standard uncertainties for the measured vapor pressures $u(p)$, based on estimated uncertainties in measuring the mass, area, and angle of inclination of the piston, are described by the expression:

$$
u(p)=\left(1.5 \cdot 10^{-4} p+0.2\right) \mathrm{Pa} .
$$

The standard uncertainties for the temperatures $u(T)$ are $0.002 \mathrm{~K}$. Contributions of the temperature uncertainties to $u(p)$ are not significant.

\subsection{Combustion calorimetry}

The experimental procedures used in the combustion calorimetry reported here have been described [12,17-19]. The enthalpy of combustion for crystalline 1-naphthol was determined in this research with a rotating-bomb calorimeter (laboratory designation BMR II) [18] and platinum-lined bomb (laboratory designation Pt-3b) [20] with an internal volume of $0.393_{4} \mathrm{dm}^{3}$ that were used without rotation. Samples of 1-naphthol were burned as pellets [21]. For each experiment, a volume of $0.0010 \mathrm{dm}^{3}$ of water was added to the bomb, and the bomb was flushed and pressurized to $3.04 \mathrm{MPa}$ with pure oxygen. The temperature rise in the combustion and calibration series were made the same within 0.1 per cent through adjustment of the sample and auxiliary substance 
masses. All experiments were completed within $0.01 \mathrm{~K}$ of $T / \mathrm{K}=298.15$. Temperatures were measured with quartz-crystal thermometry [22,23].

NIST Standard Reference Material benzoic acid (sample 39i) was used for calibration; its massic energy of combustion is $-(26434.0 \pm 3.0) \mathrm{J} \cdot \mathrm{g}^{-1}$ under certificate conditions. Conversion to standard states [24] gives $-(26413.7 \pm 3.0) \mathrm{J} \cdot \mathrm{g}^{-1}$ for $\Delta_{\mathrm{c}} U^{\mathrm{o}} / \mathrm{M}$, the massic energy of the idealized combustion reaction. The high purity of the oxygen used and preliminary bomb flushing ensured that no nitrogen oxides were formed in the calibration experiments. The energy equivalent of the calorimeter $\varepsilon$ (calor) was (16785.7 $\pm 1.2) \mathrm{J} \cdot \mathrm{K}^{-1}$ (mean and standard deviation of the mean), based on a series of six combustions. For the cotton fuse, empirical formula $\mathrm{CH}_{1.774} \mathrm{O}_{0.887}, \Delta_{\mathrm{c}} U^{\circ} / \mathrm{M}$ was $-16945 \mathrm{~J} \cdot \mathrm{g}^{-1}$. Auxiliary information, necessary for reducing apparent mass to mass, converting the energy of the actual bomb process to that of the isothermal process, and reducing to standard states, included a density $\rho$ at $T / \mathrm{K}=298.15$ of $\rho=1290 \mathrm{~kg} \cdot \mathrm{m}^{-3}$ [25] for solid 1-naphthol and an estimated value of $1.05 \cdot 10^{-8} \mathrm{~m}^{3} \cdot \mathrm{K}^{-1}$ for $\left(\partial V_{\mathrm{m}} / \partial T\right)_{\mathrm{p}}$. The heat capacity at $T / \mathrm{K}=298.15$ for 1 -naphthol used in the corrections to standard states is given in this paper as part of the adiabatic calorimetric results.

Carbon dioxide was recovered from the combustion products of each experiment, where anhydrous lithium hydroxide was used as the adsorbent [26]. The combustion products were checked for unburned carbon and other products of incomplete combustion, and none were detected. Fractional carbon dioxide recoveries were $(1.0000$ \pm 0.0001 ; mean and standard deviation of the mean) for the benzoic acid calibrations and $(0.9998 \pm 0.0001)$ for the 1-naphthol combustions. 


\section{Experimental Results}

\subsection{Heat capacities, enthalpies, triple point temperature, and derived thermodynamic functions for the condensed phases}

Measurements of enthalpy increments and derived heat capacities for 1-naphthol were made with adiabatic calorimetry for the temperature range $(4.5<T / \mathrm{K}<445)$, and included determination of the triple-point temperature $T_{\mathrm{tp}}$ and the molar enthalpy of fusion $\Delta_{\mathrm{cr}}^{\mathrm{l}} H_{\mathrm{m}}$. The density of liquid 1-naphthol under saturation pressure at temperature $T / \mathrm{K}=393\left\{\rho_{\text {sat }}=1063 \pm 10 \mathrm{~kg} \cdot \mathrm{m}^{-3}\right\}$ was determined from the sample mass and volume measured as part of the filling procedure for the sample vessel. Crystallization of 1naphthol in the calorimeter was initiated by slow cooling (approximately $0.5 \mathrm{mK} \cdot \mathrm{s}^{-1}$ ) of the liquid sample to approximately $30 \mathrm{~K}$ below $T_{\mathrm{tp}}$. Complete crystallization was obtained by maintaining the sample in the partially melted state (approximately 10 to 20 percent liquid) until ordering of the crystals was complete, as evidenced by the absence of spontaneous warming of the sample. In these experiments, the sample warmed spontaneously for approximately $5 \mathrm{~h}$, after the initial partial melting. The sample was then cooled at an effective rate of $0.5 \mathrm{mK} \cdot \mathrm{s}^{-1}$ to crystallize the liquid and was thermally cycled from approximately $100 \mathrm{~K}$ to within $3 \mathrm{~K}$ of the triple-point temperature $\left(T_{\mathrm{tp}}=\right.$ $368.485 \mathrm{~K}$ ), where it was held for a minimum of $16 \mathrm{~h}$ to provide further tempering. All of the solid-phase measurements were performed upon crystals pre-treated in this way. Excellent repeatability was observed for two separate determinations of $\Delta_{\mathrm{cr}}^{1} H_{\mathrm{m}}$, which also is indicative of complete conversion to the crystalline state.

The triple-point temperature $T_{\mathrm{tp}}$ and mole fraction purity $x$ for 1-naphthol were determined by measurement of equilibrium melting temperatures $T(F)$ as a function of 
fraction $F$ of the sample in the liquid state [27]. Equilibrium melting temperatures were determined by measuring temperatures for $\sim 1.5 \mathrm{~h}$ after an energy input and extrapolating to infinite time by assuming an exponential decay toward equilibrium. Observed temperatures at the end of the equilibration period were within $2 \mathrm{mK}$ of those extrapolated for $F$ values listed in table 3. Results indicated the presence of solid-soluble impurities, and the method of Mastrangelo and Dornte [28] was used to calculate the sample purity. Results are summarized in table 3.

Experimental molar enthalpy results for are summarized in table 4, which includes those used in the determination of the enthalpy of fusion and measurements in singlephase regions, which serve as consistency checks for the integrated heat-capacity values. Corrections for pre-melting [29] caused by impurities were made with the impurity $x_{\text {pre }}$ listed in table 2 . The value $x_{\text {pre }}$ is smaller than the sample impurity because some of the impurity is dissolved in the solid state. Results with the same series number $N$ in tables 4 and 5 were taken without interruption of adiabatic conditions.

Equilibrium was reached in less than $1 \mathrm{~h}$ for all measurements in the liquid phase and for measurements in the solid phase below $T / \mathrm{K}=325$. As the triple-point temperature $\left(T_{\mathrm{tp}}=368.48_{5} \mathrm{~K}\right)$ was approached, equilibration periods increased gradually from $1 \mathrm{~h}$ near $T / \mathrm{K}=325$ to $12 \mathrm{~h}$ near $T / \mathrm{K}=365$.

The experimental heat capacities under vapor saturation pressure $C_{\mathrm{sat}, \mathrm{m}}$ for 1naphthol are listed in table 5 and shown in figure 1 . Values in table 5 were corrected for effects of sample vaporization into the gas space of the calorimeter, although the size of this correction is small, as noted in table 2 . The values listed in table 5 were corrected for premelting with the mole fraction impurity value given in table 2 . Relative expanded 
uncertainties ( 0.95 level of confidence) for the heat-capacity measurements $U_{\mathrm{r}}\left(C_{\mathrm{sat}, \mathrm{m}}\right)$ were 0.03 at $T / \mathrm{K}=5,0.005$ at $T / \mathrm{K}=10$, and 0.001 for temperatures $T / \mathrm{K} \geq 30$.

Extrapolation of the heat-capacity results to $T \rightarrow 0 \mathrm{~K}$ was made with a plot of $C_{\mathrm{sat}, \mathrm{m}} / T$ against $T^{2}$ for temperatures below $T / \mathrm{K}=10$.

Entropies and enthalpies under vapor saturation pressure for the condensed phases relative to that of the crystals at $T / \mathrm{K} \rightarrow 0$ for 1-naphthol are listed in table 6. These were derived by integration of the smoothed heat capacities corrected for pre-melting, together with the entropy and enthalpy of fusion. Pre-melting corrections were made using standard methods [27] for solid-insoluble impurities and the mole-fraction impurity value shown in table 2 .

\subsection{Vapor pressures and derived enthalpies of vaporization}

Vapor pressures measured in this research for 1-naphthol are reported in table 7. The Wagner equation [30] in the form shown here was used to represent the vapor pressures:

$$
\ln \left(p / p_{\mathrm{c}}\right)=\left(1 / T_{\mathrm{r}}\right)\left\{\mathrm{A}\left(1-T_{\mathrm{r}}\right)+\mathrm{B}\left(1-T_{\mathrm{r}}\right)^{1.5}+\mathrm{C}\left(1-T_{\mathrm{r}}\right)^{2.5}+\mathrm{D}\left(1-T_{\mathrm{r}}\right)^{6}\right\},
$$

where $T_{\mathrm{r}}=T / T_{\mathrm{c}}$ and $T_{\mathrm{c}}$ is the critical temperature. The critical temperature $\left(T_{\mathrm{c}}=815 \mathrm{~K}\right)$ was estimated with the method of Joback [31], and the critical pressure $p_{\mathrm{c}}$ was estimated based on Waring's criterion for $T / T_{\mathrm{c}}=0.85$ [32]. This unusual form of the Wagner equation was chosen to provide better extrapolations of the vapor pressures to lower temperatures, as described later. The fitted parameters and selected critical constants are listed in table 8.

$$
\begin{aligned}
& \text { Enthalpies of vaporization } \Delta_{\mathrm{l}}^{\mathrm{g}} H_{\mathrm{m}} \text { were calculated with the Clapeyron equation: } \\
& \qquad \mathrm{d} p / \mathrm{d} T=\Delta_{\mathrm{l}}^{\mathrm{g}} H_{\mathrm{m}} /\left(T \cdot \Delta_{\mathrm{l}}^{\mathrm{g}} V_{\mathrm{m}}\right)
\end{aligned}
$$


where $\Delta_{\mathrm{l}}^{\mathrm{g}} V_{\mathrm{m}}$ is the increase in molar volume from the liquid to the vapor. The Wagnerequation fit was used to calculate $\mathrm{d} p / \mathrm{d} T$, and molar volumes for the liquid phase were estimated with the Riedel equation [33], as formulated by Hales and Townsend [34]:

$$
\rho / \rho_{\mathrm{c}}=1.0+0.85\left(1-T_{\mathrm{r}}\right)+(1.6916+0.9846 \omega)\left(1-T_{\mathrm{r}}\right)^{1 / 3}
$$

where $T_{\mathrm{c}}$ was that estimated for the vapor pressure fit. The acentric factor $\omega$ was obtained from the vapor pressure fit, and the critical density $\rho_{\mathrm{c}}$ was estimated with equation (5) and the single density for the liquid phase measured during filling of the sample vessel for the heat capacity studies. Vapor-phase volumes were calculated with the virial equation of state truncated at the third virial coefficient. Second and third virial coefficients were estimated with the corresponding-states methods of Pitzer and Curl [35] and Orbey and Vera [36], respectively. Third virial coefficients are required for calculation of the volume of gas for pressures greater than 0.1 MPa [37]. Relative expanded uncertainties ( 0.95 confidence) for the virial coefficients were estimated to be 10 percent. The derived enthalpies of vaporization are reported in table 9.

\subsection{Enthalpy of combustion and derived enthalpy of formation for the crystalline state}

Results of a typical combustion experiment for 1-napthol are listed in table 10. All measured values of $\Delta_{\mathrm{c}} U^{\circ} / \mathrm{M}$ for are reported in table 11 , where these refer to the reaction:

$$
\mathrm{C}_{10} \mathrm{H}_{8} \mathrm{O}(\mathrm{cr})+11.5 \mathrm{O}_{2}(\mathrm{~g})=10 \mathrm{CO}_{2}(\mathrm{~g})+4 \mathrm{H}_{2} \mathrm{O}(\mathrm{l})
$$

Table 11 also gives derived values of the standard energy of combustion $\Delta_{\mathrm{c}} U_{\mathrm{m}}^{\mathrm{o}}$, the standard enthalpy of combustion $\Delta_{\mathrm{c}} H_{\mathrm{m}}^{\mathrm{o}}$, and the standard enthalpy of formation $\Delta_{\mathrm{f}} H_{\mathrm{m}}^{\mathrm{o}}$ for 1-naphthol in the crystal phase. Values of $\Delta_{\mathrm{c}} U_{\mathrm{m}}^{\mathrm{o}}$ and $\Delta_{\mathrm{c}} H_{\mathrm{m}}^{\mathrm{o}}$ refer to reaction (6). Values of $\Delta_{\mathrm{f}} H_{\mathrm{m}}^{\mathrm{o}}$ refer to the reaction: 


$$
10 \mathrm{C}(\mathrm{cr} \text {, graphite })+4 \mathrm{H}_{2}(\mathrm{~g})+0.5 \mathrm{O}_{2}(\mathrm{~g})=\mathrm{C}_{10} \mathrm{H}_{8} \mathrm{O}(\mathrm{cr}) \text {. }
$$

Uncertainties given in table 11 are expressed as the "uncertainty interval" defined in reference [38]. This is equivalent to the expanded uncertainty with 0.95 level of confidence. The standard enthalpies of formation of $\mathrm{CO}_{2}(\mathrm{~g})$, and $\mathrm{H}_{2} \mathrm{O}(\mathrm{l})$ were taken to be $-(393.51 \pm 0.13) \mathrm{kJ} \cdot \mathrm{mol}^{-1}$ and $-(285.830 \pm 0.042) \mathrm{kJ} \cdot \mathrm{mol}^{-1}$, respectively, as assigned by CODATA [39].

\subsection{Thermodynamic properties for the ideal gas derived from thermophysical property measurements}

Enthalpies and entropies for 1-naphthol were calculated at selected temperatures for the ideal gas at $p=101.325 \mathrm{kPa}$ with values in tables 6 and 9 and are listed in columns 2 and 4 of table 12. The derived enthalpies and entropies for the ideal gas state were combined with the enthalpy of formation for the crystal of 1-naphthol to calculate the enthalpies, entropies, and Gibbs free energies of formation listed in columns 6, 7, and 8, respectively, of table 12. Enthalpies and entropies for $\mathrm{H}_{2}$ (equilibrium, $\mathrm{g}$ ), $\mathrm{O}_{2}(\mathrm{~g})$, and $\mathrm{C}$ (graphite) were calculated with parameters from the JANAF tables [40]. Uncertainties listed in table 12 are expanded uncertainties (0.95 confidence) and do not include uncertainties in the properties of the elements.

\section{Discussion}

\subsection{Mutual validation with computational methods}

The geometries, energies, and vibrational frequencies for 1-naphthol were calculated at the B3LYP/6-31+G(d,p) model chemistry level using Gaussian 09 software [41]. The hybrid density functional method B3LYP has been demonstrated to well predict molecular geometries and vibrational frequencies, as well as the ideal-gas entropies 
derived from them, for a range of aromatic and substituted aromatic compounds [1-5]. Full conformational analysis was performed including optimized "cis" and "trans" conformations and mapping of $\mathrm{OH}$ torsion that connects them. (In planar 1-naphthol, the $\mathrm{OH}$ hydrogen is rotated toward the position- 8 carbon in the "cis" configuration and toward the position-2 carbon in the "trans" configuration.) The predicted rotational constants compare well against the values reported by Johnson et al. [42] based on spectroscopic studies, as shown in table 13.

Consistent with the experimental consensus based on spectroscopic studies [42-45], the trans conformer is computed to be more stable than the cis. The zero-point-energy corrected difference between the energies of the conformations is computed to be 4.8 $\mathrm{kJ} \cdot \mathrm{mol}^{-1}$, which agrees with experimental estimates by Lakshminarayan et al. [44] (5.4 $\left.\mathrm{kJ} \cdot \mathrm{mol}^{-1}\right)$ and by Muzomwe et al. [45] $\left(5.1 \mathrm{~kJ} \cdot \mathrm{mol}^{-1}\right)$, but disagrees by about a factor of 2 with the value reported by Hollas and bin Hussein [43] $\left(2.6 \mathrm{~kJ} \cdot \mathrm{mol}^{-1}\right)$. The rotational barrier for the $\mathrm{OH}$ torsion in 1-naphthol has not been reported based on experiment, but the computed value of $15.7 \mathrm{~kJ} \cdot \mathrm{mol}^{-1}$ (relative to the trans conformation) compares well with the torsion barrier for phenol $\left(14.5 \mathrm{~kJ} \cdot \mathrm{mol}^{-1}\right)$ reported by Berden et al. [46].

The computed vibrational frequencies were scaled with a single factor $F=0.975$. Recently [2], we demonstrated that a single scale factor $F=0.975$ provides good accord with experimental gas-phase vibrational spectra [10] for quinoline and isoquinoline reported in the literature for all frequencies $v<2000 \mathrm{~cm}^{-1}$. Higher frequencies, which are all greater than $3000 \mathrm{~cm}^{-1}$ for most molecules, were considered unimportant because they make very little contribution to thermodynamic properties in the temperature range of interest here, $(298.15<(T / \mathrm{K})<600)$. The value $F=0.975$ was also suggested by 
Muzomwe et al. [45] for their B3LYP calculations with the similar, 6-31+G(d), basis set.

Computed vibrational frequencies for both conformers are listed in table 14. These are in good accord with vibrational spectra reported by Ram et al. [47] and Muzomwe et al., [45]; however, none of the spectra reported in the literature are for the gas phase. As we have discussed previously [48], low-frequency vibrational modes, which provide the dominant contributions to the computed thermodynamic properties, shift to lower frequencies in the gas phase relative to the liquid, solid, or a solid matrix. Consequently, use of experimental vibrational frequencies based on condensed phase spectra will provide erroneous results for calculated ideal-gas properties, and because of the vaporto-condensed phase shift to higher frequencies, these values will be low relative to the true gas-phase values.

The $\mathrm{OH}$ torsion was treated as a one-dimensional hindered rotor with angular dependencies of potential and reduced rotational constant derived from B3LYP/6$31+\mathrm{G}(\mathrm{d}, \mathrm{p})$ calculations. The resulting one-dimensional Schrödinger equation was solved numerically with the method described by Li et al. [49], yielding the discrete energy levels used for calculation of the partition function. The first 20 energy levels obtained from numerical solution of the one-dimensional Schrödinger equation for the $\mathrm{OH}$ torsion are included in table 14. The calculated potential and reduced rotational constant are plotted as a function of the angle of rotation of the $\mathrm{OH}$ group in figure 2.

Differences between ideal gas entropies based on the scaled calculated frequencies $\Delta_{0}^{T} S_{\mathrm{m}}^{\mathrm{o}}$ (computed) and those derived with the experimental measurements of this research $\Delta_{0}^{T} S_{\mathrm{m}}^{\mathrm{o}}$ (expt) (table 12) are given in figure 3. Agreement is excellent with all 
differences less than the expanded uncertainties for the experimental values. The relative expanded uncertainty for $\Delta_{0}^{T} S_{\mathrm{m}}^{\mathrm{o}}$ (expt) is $\sim 0.2$ percent for most of the temperature range. The dashed lines represent differences calculated with scaling factors $F=0.97$ and 0.98 . These values bracket the value $F=0.975$ used to calculate the filled circles and provide a measure of the sensitivity of the values of $\Delta_{0}^{T} S_{\mathrm{m}}^{\mathrm{o}}$ (computed) to small changes in $F$.

The double-headed arrow in figure 3 indicates the range of the vapor pressures measured in this research and used in the fit to the Wagner equation. Extrapolation to lower temperatures was not constrained, and as noted previously [5], the extrapolated values are sensitive to the value of the exponent for the last term of the Wagner equation. The value 6.0 was chosen as best, because the change in slope for the differences in ideal gas entropy was minimized. There are no other contributions to the computed or experiment-based values that could cause a sudden change in slope in the difference plot, as is observed with the exponent set to 5.0 (open circles in figure 3).

\subsection{Comparisons with literature melting temperatures, enthalpies of fusion, and} condensed-phase heat capacities

Normal melting temperatures have been reported more than 50 times in the literature for 1-naphthol, and the values are in general accord with those of this research, but with much larger uncertainties than those given here. The enthalpy of fusion for 1-naphthol has been reported 14 times [50-63] within the last 90 years. The method in all studies was a type of differential scanning calorimetry, except that by Andrews et al. [63] in 1926, who used a drop calorimeter. Except for the value reported by Rai and Rai [51] in 1998, all values are low relative to that of this research, as shown in table 15 . These deviations are likely due to incomplete accounting for pre-melting in the literature 
studies. Also, very few of the samples used in the literature studies were near the purity of that used in this research. It is noteworthy that the poorest result is that reported most recently in 2012 by Gupta et al. [50].

In 1906, Beck and Ebbinghaus [64] reported a crystal-to-crystal phase transition for 1-naphthol near the temperature $T / K=320$, based on visual observation of the crystals upon heating. Their interpretation of what they observed is not supported here.

Similarly, Beck and Ebbinghaus reported crystal-to-crystal phase transition temperatures for 1-amino-4-methylbenzene and 1,4-dibromobenzene. Neither of these observations is supported by later studies of heat capacities in the solid state $[65,66,67]$.

Andrews et al. [63] reported enthalpies and derived heat capacities based on drop calorimetric measurements for the solid and liquid phase of 1-naphthol for the temperature range $318<T / \mathrm{K}<453$. Their reported heat capacities are higher than those reported here, with deviations within 5 percent. These deviations are in accord with the anticipated uncertainties for method used by Andrews et al. [63].

\subsection{Comparisons with literature vapor and sublimation pressures}

Vapor pressures for 1-naphthol have been reported by May et al. [68], Terres et al.[69], and Sakoguchi et al.[70]. Deviations of the literature values from the results of the present research are shown in figure 4. Sakoguchi et al. [70] used a transpiration method and deviations approaching 10 percent of the measured values are seen. This is in accord with typical uncertainties for this method. Large deviations between 10 and 25 percent are seen for the results of Terres et al. [69], who measured vapor pressures in a closed system with a mercury manometer. It is unfortunate that these results are of low 
quality because the authors reported results for 39 phenolic compounds, which is a sizable portion of the vapor-pressure literature for this important compound class.

Sublimation pressures were calculated in the present research through combination of vapor pressures extrapolated to below $T_{\mathrm{tp}}$ \{parameters of table 8 with equation (3)\}, the thermodynamic functions for the crystals (table 6), and thermodynamic functions for the supercooled liquid based on linearly extrapolated heat capacities for the liquid phase (table 6 and plotted in figure 1). The method has been described in detail previously [71]. Sublimation pressures calculated here are represented with the following equation.

$$
\ln \left(p / p^{\circ}\right)=4.3525 \cdot 10^{7} \cdot(T / K)^{-3}-5.0988 \cdot 10^{5} \cdot(T / K)^{-2}-9.3245 \cdot 10^{3} \cdot(T / K)^{-1}++32.7496,(8)
$$

where $p^{\circ}$ is $1 \mathrm{~Pa}$ and the range of validity is $290<(T / \mathrm{K})<T_{\text {tp }}$. The estimated expanded uncertainties are $0.02 \cdot p$ at $T_{\mathrm{tp}}$ and $0.05 \cdot p$ at $T / \mathrm{K}=290$ for these values.

Sublimation pressures have been reported by Colomina et al. [72] and Sakoguchi et al. [70] with the gas saturation and Knudsen effusion methods, respectively. Comparisons with the values calculated with equation 8 are shown in figure 4. Deviations are in accord with typical uncertainties associated with these techniques.

\subsection{Comparisons with literature sublimation enthalpies}

Enthalpies of sublimation at temperature $T / \mathrm{K}=298.15$ were reported by Colomina et al. [72] $\left\{\Delta_{\mathrm{cr}}^{\mathrm{g}} H_{\mathrm{m}}=(91.2 \pm 0.4) \mathrm{kJ} \cdot \mathrm{mol}^{-1}\right\}$ based on the slope of their measured sublimation pressures, and by Arshadi $[73]\left\{\Delta_{\mathrm{cr}}^{\mathrm{g}} H_{\mathrm{m}}=(89.1 \pm 1.7) \mathrm{kJ} \cdot \mathrm{mol}^{-1}\right\}$ with a combined mass spectrometric and Knudsen effusion method. Both values are near, but slightly lower than that derived here, $\left\{\Delta_{\mathrm{cr}}^{\mathrm{g}} H_{\mathrm{m}}=(93.27 \pm 0.8) \mathrm{kJ} \cdot \mathrm{mol}^{-1}\right\}$. The "uncertainties" reported by Colomina et al. [72] and Arshadi [73] are repeatabilities, which are only the lower limit for the standard uncertainty. 


\subsection{Comparisons with literature densities for the liquid}

Densities for the liquid phase of 1-naphthol were measured by Beck [74] in 1907 for the temperature range $368<T / K<413$. Based on a linear fit of the reported density values $\rho$, the repeatability is $\sim 0.002 \cdot \rho$, and the estimated expanded uncertainty $(0.95$ confidence) is $\sim 0.005 \cdot \rho$. The value determined in the present research as part of sample loading for the heat capacity studies is within the scatter of the values reported by Beck more than 100 years ago.

\subsection{Comparisons with literature enthalpies of combustion}

The enthalpy of combustion for 1-naphthol has been studied previously with oxygen-bomb calorimetry by Leman and Lepoutre [75], Colomina et al. [72], Ribeiro da Silva et al.[76], and Balcan et al. [77]. Agreement between the results of this research, Colomina et al. [72], and Ribeiro da Silva et al. [76] is excellent, as seen in Table 15. The value from Balcan et al. [77] is consistent, but the uncertainty is large, while the early value reported by Leman and Lepoutre [75] is inconsistent with all others.

\section{Conclusion}

Computational chemistry is a powerful tool for evaluation of thermodynamic properties in the ideal-gas state, and for rigid molecules, such as that studied in this research, relative expanded uncertainties near 0.1 percent for $\Delta_{0}^{T} S_{\mathrm{m}}^{\mathrm{o}}$ can be achieved. With the present results, this is now demonstrated successfully for a hyrdroxy-aromatic.

\section{Acknowledgements}

We acknowledge the contributions of An (Andy) Nguyen in the vapor-pressure measurements, Norris K. Smith in the combustion study, I. Alex Hossenlopp in vaportransfer of the samples prior to the physical property measurements, and Stephen E. 
Knipmeyer for maintenance of all apparatus. The authors gratefully acknowledge the Office of Fossil Energy of the U.S. Department of Energy (DOE) for financial support of the experimental studies. This research was funded within the Processing and Downstream Operations section of the Advanced Oil Recovery (AOR) program. The experiments were completed through BDM-Oklahoma under its contract with DOE for Management and Operations of the National Oil and Related Programs (NORP), Contract Number DE-AC22-94C91008. Manuscript preparation and all computations were done at NIST. 


\section{References}

[1] R.D. Chirico, R.D. Johnson III, W.V. Steele, J. Chem. Thermodyn. 39 (2007) 698711.

[2] R.D. Chirico, A.F. Kazakov, W.V. Steele, J. Chem. Thermodyn. 42 (2010) 571581.

[3] R.D. Chirico, A.F. Kazakov, W.V. Steele, J. Chem. Thermodyn. 42 (2010) 581590.

[4] R.D. Chirico, A.F. Kazakov, W.V. Steele, J. Chem. Thermodyn. 73 (2014) 241254.

[5] R.D. Chirico, A.F. Kazakov, W.V. Steele, J. Chem. Thermodyn. 54 (2012) 278287.

[6] W.V. Steele, R.D. Chirico, A.B. Cowell, A. Nguyen, S. E.Knipmeyer, J. Chem. Thermodyn. 36 (2004) 497-509.

[7] M.E. Wieser, N. Holden, T.B. Coplen, J.K. Böhlke, M. Berglund, W.A. Brand, P. De Bièvre, M. Gröning, R.D. Loss, J. Meija, T. Hirata, T. Prohaska, R. Schoenberg, G. O’Connor, T. Walczyk, S. Yoneda, X-K. Zhu, Pure Appl. Chem. 85 (2013) 1047-1078.

[8] 2010 CODATA Recommended Values: http://physics.nist.gov/cgi-bin/cuu/Value?r (Accessed March 8, 2012).

[9] Metrologia 5 (1969) 35-44.

[10] R.N. Goldberg, R.D. Weir, Pure Appl. Chem. 64 (1992) 1545-1562.

[11] F.L. McCrackin, S.S. Chang, Rev. Sci. Instrum. 46 (1975) 550-553.

[12] W.V. Steele, D.G. Archer, R.D. Chirico, W.B. Collier, I.A. Hossenlopp, A. Nguyen, N.K. Smith, B.E. Gammon, J. Chem. Thermodyn. 20 (1988) 1233-1264

[13] A.G. Osborn, D.R. Douslin, J. Chem. Eng. Data 11 (1966) 502-509.

[14] W. Wagner, A. Pruss, J. Phys. Chem. Ref. Data 31 (2002) 387-535. 
[15] D.R. Douslin, J.P. McCullough, US Bureau of Mines. Report of Investigation 6149, 1963, pp. 11.

[16] D.R. Douslin, A.G. Osborn, J. Sci. Instrum. 42 (1965) 369-373.

[17] W.D. Good, J. Chem. Eng. Data 14 (1969) 14, 231-235.

[18] W.D. Good, J. Chem. Eng. Data 17 (1972) 28-31.

[19] W.D. Good, N.K. Smith, J. Chem. Eng. Data 14 (1969) 102-106.

[20] W.D. Good, D.R. Douslin, D.W. Scott, A. George, J.L. Lacina, J.P. Dawson, J. Phys. Chem. 63 (1959) 1133-1138.

[21] G.B. Guthrie, D.W. Scott, W.N. Hubbard, C. Katz, J.P. McCullough, M.E. Gross, K.D. Williamson, G. Waddington, Thermodynamic Properties of Furan. J. Am. Chem. Soc. 1952, 74, 4662-4669.

[22] N.K. Smith, R.C. Stewart, Jr., A.G. Osborn, D.W. Scott, J. Chem. Thermodyn. 12 (1980) 919-926.

[23] R.D. Chirico, I.A. Hossenlopp, A. Nguyen, M.M. Strube, W.V. Steele, Dept. of Energy Report No. NIPER-247, April 1987. (NTIS Report No. DE87001252.)

[24] W.N. Hubbard, D.W. Scott, G. Waddington, in F.D. Rossini, (Ed) Experimental Thermochemistry, Interscience, New York, 1956, Chapter 5, pp. 75-128. For those who cannot obtain a copy of this reference, the following source details the items in question, but in an earlier version in which some of the ancillary datum are inaccurate. W.N. Hubbard, D.W. Scott, W. Waddington. Reduction to Standard States (at $25^{\circ} \mathrm{C}$ ) of Bomb Calorimetric Data for Compounds of Carbon, Hydrogen, Oxygen and Sulfur J. Phys. Chem., 1954, 58, 152-162.

[25] B. Robinson, A. Hargreaves, Acta Cryst. B, 28 (1964) 944-946.

[26] W.D. Good, N.K. Smith, J. Chem. Eng. Data 14 (1969) 101-106.

[27] J.P. McCullough, G. Waddington, Anal. Chim. Acta 17 (1957) 80-96.

[28] S.V.R. Mastrangelo, R.W. Dornte, J. Am. Chem. Soc. 77 (1955) 6200. 
[29] E.F. Westrum Jr., G.T. Furukawa, J.P. McCullough, in: J.P. McCullough, D.W. Scott (Eds.), Experimental Thermodynamics, vol. 1, Butterworths, London, 1968 (Chapter 5).

[30] W. Wagner, Cryogenics 13 (1973) 470-482.

[31] K.G. Joback, R.C. Reid, Chem. Eng. Comm. 57 (1987) 233-243.

[32] W. Waring, Ind. Eng. Chem. 46 (1954) 762-763.

[33] L. Riedel, Chem.-Ing.-Tech. 26 (1954) 259-264.

[34] J.L. Hales, R. Townsend, J. Chem. Thermodyn. 4 (1972) 763-772.

[35] K.S. Pitzer, R.F. Curl, Jr., J. Am. Chem. Soc. 79 (1957) 2369-2370.

[36] H. Orbey, J. H. Vera, AIChE J. 29 (1983) 107-113.

[37] R.D. Chirico, W.V. Steele, Ind. Eng. Chem. Res. 33 (1994) 157-167.

[38] F.D. Rossini, Assignment of Uncertainities to Thermochemical Data. in F.D Rossini. (Ed) Experimental Thermochemistry, Interscience, New York, 1956, pp. 297-320, Chapter 14.

[39] J.D. Cox, D.D Wagman, V.A. Medvedev. Eds; CODATA Key Values for Thermodynamics. Hemisphere: New York 1989.

[40] M.W. Chase Jr., NIST-JANAF Thermochemical Tables. Fourth edition. Part I. AlCo and Part II, Cr-Zr. Journal of Physical and Chemical Reference Data Monograph No. 9, Springer-Verlag: New York, 1998.

[41] M. J. Frisch, G. W. Trucks, H. B. Schlegel, G. E. Scuseria, M. A. Robb, J. R. Cheeseman, G. Scalmani, V. Barone, B. Mennucci, G. A. Petersson, H. Nakatsuji, M. Caricato, X. Li, H. P. Hratchian, A. F. Izmaylov, J. Bloino, G. Zheng, J. L. Sonnenberg, M. Hada, M. Ehara, K. Toyota, R. Fukuda, J. Hasegawa, M. Ishida, T. Nakajima, Y. Honda, O. Kitao, H. Nakai, T. Vreven, J. A. Montgomery, Jr., J. E. Peralta, F. Ogliaro, M. Bearpark, J. J. Heyd, E. Brothers, K. N. Kudin, V. N. Staroverov, T. Keith, R. Kobayashi, J. Normand, K. Raghavachari, A. Rendell, J. C. Burant, S. S. Iyengar, J. Tomasi, M. Cossi, N. Rega, J. M. Millam, M. Klene, J. 
E. Knox, J. B. Cross, V. Bakken, C. Adamo, J. Jaramillo, R. Gomperts, R. E. Stratmann, O. Yazyev, A. J. Austin, R. Cammi, C. Pomelli, J. W. Ochterski, R. L. Martin, K. Morokuma, V. G. Zakrzewski, G. A. Voth, P. Salvador, J. J. Dannenberg, S. Dapprich, A. D. Daniels, O. Farkas, J. B. Foresman, J. V. Ortiz, J. Cioslowski, and D. J. Fox, Gaussian 09, Revision C.01, Gaussian, Inc., Wallingford CT, 2010.

[42] J.R. Johnson, K.D. Jordan, D.F. Plusquellic, D.W. Pratt, J. Chem. Phys. 93 (1990) 2258-2273.

[43] J. M. Hollas, M.Z. bin Hussein, J. Mol. Spectrosc. 127 (1988) 497-508.

[44] C. Lakshminarayan, J.M. Smith, J.L. Kee, Chem. Phys. Lett. 182 (1991) 656-662.

[45] M. Muzomwe, B. Boeckx, G. Maes, O.E. Kasende, Spectrochim. Acta A: Mol. Biomol. Spectrosc. 108 (2013) 14-19.

[46] G. Berden, W.L. Meerts, M. Schmitt, K. Kleinermanns, J. Chem. Phys. 104 (1996) 972-982.

[47] S. Ram, V.N. Pandey, S.N. Thakur, Pramana 20 (1983) 163-174.

[48] R.D. Chirico, T.D. Klots, S.E. Knipmeyer, A. Nguyen, W.V. Steele, J. Chem. Thermodyn. 30 (1998) 535-556.

[49] J. Li, A. Kazakov, F.L. Dryer, J. Phys. Chem. A 108 (2004) 7671-7680.

[50] P. Gupta, T. Agrawal, S.S. Das, N.B. Singh, J. Chem. Thermodyn. 48 (2012) 291299.

[51] U.S. Rai, R.N. Rai, J. Therm. Anal. Calorim. 53 (1998) 883-893.

[52] B.L. Sharma, N.K. Sharma, M. Rambal, Thermochim. Acta 206 (1992) 71-84.

[53] U.S. Rai, S. George, J. Mater. Sci. 27 (1992) 711-718.

[54] K.D. Mandal, Pol. J. Chem. 66 (1992) 1673-1681

[55] U.S. Rai, K.D. Mandal, Mol. Cryst. Liq. Cryst. 182B (1990) 387-404. 
[56] J.R. Donnelly, L.A. Drewes, R.L. Johnson, W.D. Munslow, K.K. Knapp, Thermochim. Acta 167 (1990) 155-187.

[57] U.S. Rai, K.D. Mandal, N.P. Singh, J. Therm. Anal. 35 (1989) 1687-1697.

[58] N. Singh, B.M. Shukla, N.P. Singh, N.B. Singh, Bull. Soc. Chim. Fr. (1985) 626628.

[59] S.C. Khetarpal, K. Lal, H.L. Bhatnagar, Aust. J. Chem., 32 (1979) 49-57.

[60] N.B. Singh, P. Rastogi, N.B. Singh, Krist. Tech. 13 (1978) 1169-1174.

[61] N.B. Singh, N.B. Singh, J. Cryst. Growth 28 (1975) 267-270.

[62] P. Pacor, Anal. Chim. Acta 37 (1967) 200-208.

[63] D.H. Andrews, G. Lynn, J. Johnston, J. Am. Chem. Soc. 48 (1926) 1274-1287.

[64] K. Beck, K. Ebbinghaus, Ber. Dtch. Chem. Ges. 39 (1906) 3870-3877.

[65] M. Censky, M. Lipovska, H.-G. Schmidt, V. Ruzicka, G. Wolf, J. Therm. Anal. Calorim. 63 (2001) 879-899.

[66] L.M. Meva'a, A. Lichanot, Thermochim. Acta 158 (1990) 335-345.

[67] P.R. van der Linde, J.C. van Miltenburg, G.J.K. van den Berg, H.A.J. Oonk, J. Chem. Eng. Data 50 (2005) 164-172.

[68] O.E. May, J.F.T. Berliner, D.F.J. Lynch, J. Am. Chem. Soc. 49 (1927) 1012-1016.

[69] E. Terres, F. Gebert, H. Hulsemann, H. Petereit, H. Toepsch, W. Ruppert, Brennst.-Chem. 36 (1955) 272-274.

[70] A. Sakoguchi, Y. Iwai, J. Takenaka, Y. Arai, Kagaku Kogaku Ronbunshu 15 (1989) 166-169.

[71] R.D. Chirico, S.E. Knipmeyer, A. Nguyen, W.V. Steele, J. Chem. Thermodyn. 21 (1989) 1307-1331.

[72] M. Colomina, M.V. Roux, C. Turrion, J. Chem. Thermodyn. 6 (1974) 571-576.

[73] M.R. Arshadi, J. Chem. Soc., Faraday Trans. 170 (1974) 1569-1571. 
[74] K. Beck, Z. Phys. Chem., Stoechiom. Verwandtschaftsl. 58 (1907) 425-441.

[75] A. Leman, G. Lepoutre, C.R. Hebd. Seances Acad. Sci. 226 (1948) 1976-1978.

[76] M.A.V. Ribeiro da Silva, M.D.M.C. Ribeiro da Silva, G. Pilcher, J. Chem. Thermodyn. 20 (1988) 969-974.

[77] M. Balcan, S. Arzik, T. Altunata, Thermochim. Acta, 278 (1996) 49-56. 


\section{TABLE 1}

Summary of experimental results reported in this research for 1-naphthol.

Property Method Temperature Range/K

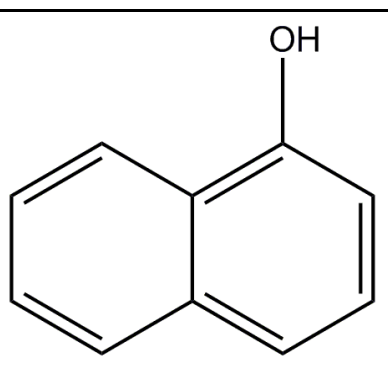

\begin{tabular}{lcc}
\hline heat capacity & $\begin{array}{c}\text { adiabatic calorimetry } \\
\text { triple-point temperature }\end{array}$ & adiabatic calorimetry \\
enthalpy of fusion & adiabatic calorimetry \\
vapor pressure & inclined-piston manometry & 370 to 440 \\
vapor pressure & comparative ebulliometry & 429 to 570 \\
enthalpy of combustion & oxygen-bomb calorimetry & 298.15 \\
\hline
\end{tabular}




\section{TABLE 2}

Calorimeter and sample characteristics for adiabatic calorimetric studies on 1-naphthol ${ }^{a}$

\begin{tabular}{lc}
\hline$m / \mathrm{g}$ & 49.965 \\
$V_{\mathrm{i}}(298.15 \mathrm{~K}) / \mathrm{cm}^{3}$ & 59.06 \\
$T_{\mathrm{cal}} / \mathrm{K}$ & 299.7 \\
$p_{\text {cal }} / \mathrm{kPa}$ & 4.65 \\
$r\left(T_{\max }\right)$ & 3.5 \\
$r_{\min }$ & 1.7 \\
$10^{2} \cdot(\delta C / C)_{\max }$ & 0.012 \\
$x_{\mathrm{pre}}$ & $0.0004_{5}$ \\
\hline
\end{tabular}

${ }^{a} m$ is the sample mass; $V_{\mathrm{i}}$ is the internal volume of the calorimeter vessel; $T_{\text {cal }}$ is the temperature of the calorimeter when sealed; $p_{\text {cal }}$ is the pressure of the helium and sample when sealed; $r\left(T_{\max }\right)$ is the ratio of the heat capacity of the full calorimeter to that of the empty at the highest temperature $T_{\max } \approx 445 \mathrm{~K}$ of these measurements; $r_{\min }$ is the minimum value of $r$ observed in this study; $(\delta C / C)_{\max }$ is the vaporization correction at the highest temperature measured (i.e., $T_{\max } \approx 445 \mathrm{~K}$ ); and $x_{\text {pre }}$ is the mole-fraction impurity used for pre-melting corrections. 
TABLE 3

Melting-study summary for 1-naphthol ${ }^{a}$

\begin{tabular}{cr}
\hline$F$ & $T(F) / \mathrm{K}$ \\
\hline 0.2050 & 368.341 \\
0.3318 & 368.389 \\
0.4976 & 368.415 \\
0.6440 & 368.428 \\
0.7903 & 368.438 \\
& \\
$T_{\text {tp }}=\left(368.48_{5} \pm 0.02\right) \mathrm{K}^{b}$ \\
\multicolumn{3}{c}{$K=0.07$} \\
\multicolumn{3}{c}{$x=0.9990$} \\
\hline
\end{tabular}

${ }^{a} \quad F$ is the fraction melted at observed temperature $T(\mathrm{~F}), T_{\mathrm{tp}}$ is the triple-point temperature of pure 1-naphthol, $x$ is the derived mole-fraction purity of the sample, $\mathrm{K}$ is the distribution coefficient between the solid and liquid phase for the impurity, as defined in reference 28 .

$b$ The uncertainty is the expanded uncertainty with 0.95 level of confidence. 


\section{TABLE 4}

Measurements of molar energy increment $\Delta_{\mathrm{tot}} U_{\mathrm{m}}$ and derived results for 1-naphthol

\begin{tabular}{|c|c|c|c|c|c|c|}
\hline \multirow{2}{*}{$\mathrm{N}^{a}$} & \multirow{2}{*}{$\mathrm{h}^{b}$} & \multirow{2}{*}{$\frac{T_{\mathrm{i}}}{\mathrm{K}}$} & \multirow{2}{*}{$\frac{T_{\mathrm{f}}}{\mathrm{K}}$} & \multirow{2}{*}{$\frac{T_{\mathrm{trs}}}{\mathrm{K}}$} & \multirow{2}{*}{$\frac{\Delta_{\mathrm{tot}} H_{\mathrm{m}}{ }^{c}}{\mathrm{~kJ} \cdot \mathrm{mol}^{-1}}$} & \multirow{2}{*}{$\frac{\Delta_{\mathrm{trs}} H_{\mathrm{m}}{ }^{d}}{\mathrm{~kJ} \cdot \mathrm{mol}^{-1}}$} \\
\hline & & & & & & \\
\hline \multicolumn{7}{|c|}{ single-phase measurements in the crystal phase } \\
\hline 5 & 1 & 51.409 & 117.576 & & 3.649 & 0.001 \\
\hline 5 & 1 & 117.570 & 216.377 & & 9.550 & -0.001 \\
\hline 5 & 1 & 216.373 & 310.068 & & 14.268 & 0.002 \\
\hline 5 & 1 & 309.974 & 363.721 & & 10.547 & 0.000 \\
\hline \multicolumn{7}{|c|}{ crystal-to-liquid phase transition } \\
\hline 3 & 3 & 364.640 & 371.902 & $368.48_{5}$ & 26.036 & 24.256 \\
\hline \multirow[t]{2}{*}{5} & 6 & 363.664 & 370.992 & & 25.989 & 24.257 \\
\hline & & & & & average & 24.257 \\
\hline \multicolumn{7}{|c|}{ single-phase measurements in the liquid phase } \\
\hline 5 & 1 & 373.450 & 440.126 & & 19.357 & -0.004 \\
\hline
\end{tabular}

a Adiabatic series number.

$b \quad$ Number of heating increments.

$c \Delta_{\mathrm{tot}} H_{\mathrm{m}}$ is the molar energy input from the initial temperature $T_{\mathrm{i}}$ to the final temperature $T_{\mathrm{f}}$. The relative expanded uncertainty for $\Delta_{\mathrm{tot}} H_{\mathrm{m}}$ is 0.001 with 0.95 level of confidence.

${ }^{d} \Delta_{\mathrm{trs}} H_{\mathrm{m}}$ is the net molar enthalpy of transition at the transition temperature $T_{\text {trs }}$ or the excess enthalpy for single-phase measurements relative to the heat-capacity curve described in the text and defined in table 6. 


\section{TABLE 5}

Molar heat capacities $C_{\mathrm{sat}, \mathrm{m}}$ at vapor-saturation pressure measured with adiabatic calorimetry for 1-naphthol $\left(R=8.3144621 \mathrm{~J} \cdot \mathrm{K}^{-1} \cdot \mathrm{mol}^{-1}\right)^{a}$

\begin{tabular}{|c|c|c|c|c|c|c|c|}
\hline$N^{b}$ & $\langle T\rangle / \mathrm{K}$ & $\Delta T / \mathrm{K}$ & $C_{\mathrm{sat}, \mathrm{m}} / R^{c}$ & $\mathbf{N}^{b}$ & $\langle T>/ \mathrm{K}$ & $\Delta T / \mathrm{K}$ & $C_{\mathrm{sat}, \mathrm{m}} / R^{c}$ \\
\hline \multicolumn{8}{|c|}{ crystal } \\
\hline 4 & 4.908 & 0.944 & 0.048 & 2 & 91.406 & 8.713 & 7.073 \\
\hline 4 & 5.887 & 0.831 & 0.081 & 2 & 100.480 & 9.332 & 7.576 \\
\hline 4 & 6.773 & 0.830 & 0.119 & 2 & 110.075 & 9.682 & 8.113 \\
\hline 4 & 7.696 & 0.952 & 0.170 & 2 & 119.949 & 10.057 & 8.685 \\
\hline 4 & 8.736 & 1.088 & 0.240 & 2 & 130.138 & 10.165 & 9.278 \\
\hline 4 & 9.852 & 1.117 & 0.331 & 2 & 140.305 & 10.162 & 9.891 \\
\hline 4 & 11.020 & 1.194 & 0.440 & 2 & 150.416 & 10.049 & 10.504 \\
\hline 4 & 12.261 & 1.280 & 0.561 & 2 & 160.427 & 9.963 & 11.145 \\
\hline 4 & 13.566 & 1.325 & 0.702 & 2 & 170.361 & 9.893 & 11.792 \\
\hline 4 & 14.975 & 1.487 & 0.866 & 2 & 180.295 & 9.965 & 12.448 \\
\hline 4 & 16.553 & 1.668 & 1.053 & 2 & 190.327 & 10.042 & 13.125 \\
\hline 4 & 18.300 & 1.827 & 1.265 & 2 & 200.452 & 10.123 & 13.819 \\
\hline 4 & 20.232 & 2.040 & 1.492 & 2 & 210.564 & 10.084 & 14.524 \\
\hline 4 & 22.381 & 2.262 & 1.749 & 2 & 220.639 & 10.053 & 15.230 \\
\hline 4 & 24.769 & 2.517 & 2.028 & 2 & 230.685 & 10.030 & 15.951 \\
\hline 4 & 27.437 & 2.821 & 2.333 & 2 & 240.710 & 10.012 & 16.663 \\
\hline 4 & 30.379 & 3.069 & 2.650 & 2 & 250.730 & 10.000 & 17.393 \\
\hline 4 & 33.629 & 3.437 & 2.984 & 2 & 260.741 & 9.994 & 18.124 \\
\hline 4 & 37.255 & 3.822 & 3.340 & 2 & 270.623 & 9.771 & 18.843 \\
\hline 4 & 41.280 & 4.232 & 3.701 & 2 & 280.511 & 10.005 & 19.570 \\
\hline 4 & 45.762 & 4.726 & 4.097 & 2 & 290.517 & 10.012 & 20.305 \\
\hline 4 & 50.766 & 5.279 & 4.487 & 2 & 300.534 & 10.026 & 21.044 \\
\hline 2 & 51.971 & 4.279 & 4.579 & 2 & 310.566 & 10.044 & 21.747 \\
\hline 4 & 56.324 & 5.836 & 4.895 & 3 & 320.582 & 10.290 & 22.446 \\
\hline 2 & 56.459 & 4.666 & 4.905 & 3 & 331.019 & 10.309 & 23.171 \\
\hline 2 & 61.849 & 6.087 & 5.291 & 3 & 341.471 & 10.326 & 23.888 \\
\hline 2 & 68.376 & 6.934 & 5.702 & 3 & 351.788 & 10.080 & 24.695 \\
\hline 2 & 75.616 & 7.213 & 6.144 & 3 & 360.698 & 7.418 & 25.320 \\
\hline 2 & 83.136 & 7.814 & 6.604 & & & & \\
\hline \multicolumn{8}{|c|}{0.004 liquid } \\
\hline 5 & 375.438 & 8.920 & 33.815 & 6 & 405.805 & 16.860 & 34.885 \\
\hline 3 & 375.526 & 7.235 & 33.820 & 6 & 423.589 & 18.731 & 35.521 \\
\hline 3 & 382.755 & 7.205 & 34.067 & 6 & 438.901 & 11.935 & 36.065 \\
\hline 6 & 389.876 & 15.003 & 34.322 & & & & \\
\hline
\end{tabular}

$a$ The relative expanded uncertainty for the heat capacities $U_{\mathrm{r}}\left(C_{\mathrm{sat}, \mathrm{m}}\right)=0.03$ at $T / \mathrm{K}=5$, 0.005 at $T / \mathrm{K}=10$, and 0.001 for temperatures $T / \mathrm{K} \geq 30$ with 0.95 level of confidence. The standard uncertainty in the mean temperatures $u(\langle T\rangle) / \mathrm{K}=0.01$.

$b$ Adiabatic series number.

${ }^{c}$ Average heat capacity for a temperature increment of $\Delta T$ with a mean temperature $\langle T\rangle$. 
TABLE 6

Molar thermodynamic functions at vapor-saturation pressure for 1-naphthol $\left(R=8.3144621 \mathrm{~J} \cdot \mathrm{K}^{-1} \cdot \mathrm{mol}^{-1}\right)^{a}$

\begin{tabular}{|c|c|c|c|c|c|c|c|}
\hline$T / \mathrm{K}$ & $C_{\mathrm{sat}, \mathrm{m}} / R$ & $\Delta_{0}^{T} S_{\mathrm{m}} / R$ & $\Delta_{0}^{T} H_{\mathrm{m}} / R T$ & $T / \mathrm{K}$ & $C_{\mathrm{sat}, \mathrm{m}} / R$ & $\Delta_{0}^{T} S_{\mathrm{m}} / R$ & $\Delta_{0}^{T} H_{\mathrm{m}} / R T$ \\
\hline \multicolumn{8}{|c|}{ crystal } \\
\hline 5.00 & 0.049 & 0.014 & 0.011 & 160.00 & 11.117 & 11.675 & 6.017 \\
\hline 10.00 & 0.344 & 0.121 & 0.091 & 180.00 & 12.429 & 13.060 & 6.657 \\
\hline 20.00 & 1.465 & 0.687 & 0.486 & 200.00 & 13.788 & 14.439 & 7.301 \\
\hline 30.00 & 2.610 & 1.502 & 1.007 & 220.00 & 15.186 & 15.819 & 7.954 \\
\hline 40.00 & 3.589 & 2.391 & 1.534 & 240.00 & 16.613 & 17.201 & 8.617 \\
\hline 50.00 & 4.430 & 3.286 & 2.032 & 260.00 & 18.070 & 18.588 & 9.288 \\
\hline 60.00 & 5.161 & 4.158 & 2.493 & 280.00 & 19.532 & 19.981 & 9.967 \\
\hline 70.00 & 5.803 & 5.003 & 2.921 & 298.15 & 20.869 & 21.249 & 10.590 \\
\hline 80.00 & 6.414 & 5.818 & 3.319 & 300.00 & 21.004 & 21.379 & 10.654 \\
\hline 90.00 & 6.995 & 6.608 & 3.696 & 320.00 & 22.405 & 22.779 & 11.345 \\
\hline 100.00 & 7.550 & 7.373 & 4.054 & 340.00 & 23.808 & 24.179 & 12.036 \\
\hline 120.00 & 8.687 & 8.849 & 4.730 & 360.00 & 25.277 & 25.581 & 12.731 \\
\hline 140.00 & 9.872 & 10.277 & 5.379 & $368.485^{b}$ & 25.926 & 26.178 & 13.027 \\
\hline \multicolumn{8}{|c|}{ liquid } \\
\hline $298.15^{b}$ & 31.071 & 27.259 & 18.261 & 440.00 & 36.104 & 40.267 & 23.202 \\
\hline $300.00^{b}$ & 31.137 & 27.452 & 18.340 & $460.00^{b}$ & 36.811 & 41.887 & 23.778 \\
\hline $320.00^{b}$ & 31.846 & 29.484 & 19.162 & $480.00^{b}$ & 37.521 & 43.469 & 24.336 \\
\hline $340.00^{b}$ & 32.556 & 31.436 & 19.929 & $500.00^{b}$ & 38.230 & 45.015 & 24.878 \\
\hline $360.00^{b}$ & 33.265 & 33.317 & 20.650 & $520.00^{b}$ & 38.940 & 46.528 & 25.405 \\
\hline $368.485^{b}$ & 33.570 & 34.095 & 20.944 & $540.00^{b}$ & 39.649 & 48.011 & 25.919 \\
\hline 380.00 & 33.973 & 35.134 & 21.333 & $560.00^{b}$ & 40.358 & 49.466 & 26.422 \\
\hline 400.00 & 34.681 & 36.895 & 21.983 & $580.00^{b}$ & 41.068 & 50.895 & 26.915 \\
\hline 420.00 & 35.393 & 38.604 & 22.604 & $600.00^{b}$ & 41.777 & 52.299 & 27.399 \\
\hline
\end{tabular}

a Relative expanded uncertainties for all properties are 0.03 at $T / \mathrm{K}=5,0.005$ at $T / \mathrm{K}=$ 10 , and 0.001 for temperatures $T / \mathrm{K} \geq 30$ with 0.95 level of confidence. The standard uncertainty for the temperatures $u(T) / \mathrm{K}=0.01$.

$b$ Values at this temperature were calculated with linearly extrapolated heat capacities. 


\section{TABLE 7}

Vapor pressure results for 1-naphthol ${ }^{\text {a }}$

\begin{tabular}{|c|c|c|c|c|c|}
\hline Method & $T / \mathrm{K}$ & $p / \mathrm{kPa}$ & $U(p) / \mathrm{kPa}$ & $\Delta p / \mathrm{kPa}$ & $\Delta T / \mathrm{K}$ \\
\hline IP & 369.980 & 0.1033 & 0.0004 & -0.0012 & \\
\hline IP & 373.122 & 0.1259 & 0.0004 & -0.0001 & \\
\hline IP & 374.970 & 0.1406 & 0.0004 & 0.0004 & \\
\hline IP & 383.134 & 0.2221 & 0.0004 & 0.0000 & \\
\hline IP & 384.975 & 0.2455 & 0.0004 & -0.0001 & \\
\hline IP & 393.127 & 0.3779 & 0.0006 & -0.0001 & \\
\hline IP & 394.975 & 0.4163 & 0.0006 & 0.0008 & \\
\hline IP & 403.120 & 0.6229 & 0.0006 & 0.0002 & \\
\hline IP & 404.964 & 0.6815 & 0.0006 & 0.0010 & \\
\hline IP & 408.127 & 0.7902 & 0.0006 & -0.0004 & \\
\hline IP & 413.123 & 0.9955 & 0.0008 & -0.0007 & \\
\hline IP & 414.970 & 1.0854 & 0.0008 & 0.0023 & \\
\hline IP & 418.116 & 1.2487 & 0.0008 & 0.0023 & \\
\hline IP & 423.115 & 1.5509 & 0.0008 & 0.0013 & \\
\hline IP & 424.962 & 1.6797 & 0.0010 & 0.0029 & \\
\hline Decane & 429.202 & 2.0002 & 0.0006 & -0.0028 & 0.12 \\
\hline IP & 429.963 & 2.0708 & 0.0010 & 0.0038 & \\
\hline IP & 434.966 & 2.5374 & 0.0012 & 0.0042 & \\
\hline Decane & 436.266 & 2.6663 & 0.0006 & -0.0018 & 0.07 \\
\hline IP & 439.957 & 3.0908 & 0.0014 & 0.0057 & \\
\hline Decane & 446.766 & 4.0003 & 0.0010 & -0.0012 & 0.04 \\
\hline Decane & 454.597 & 5.3335 & 0.0012 & 0.0011 & 0.03 \\
\hline Decane & 466.259 & 7.9994 & 0.0016 & 0.0019 & 0.02 \\
\hline Decane & 475.013 & 10.666 & 0.002 & 0.000 & 0.02 \\
\hline Decane & 482.077 & 13.332 & 0.003 & 0.003 & 0.01 \\
\hline Decane & 489.420 & 16.665 & 0.003 & 0.003 & 0.01 \\
\hline Decane & 495.526 & 19.932 & 0.004 & -0.001 & 0.02 \\
\hline Decane & 503.548 & 25.020 & 0.004 & -0.002 & 0.02 \\
\hline Decane & 503.551 & 25.021 & 0.004 & -0.001 & 0.04 \\
\hline Water & 511.628 & 31.174 & 0.006 & -0.002 & 0.05 \\
\hline Water & 519.753 & 38.561 & 0.008 & -0.001 & 0.06 \\
\hline Water & 527.934 & 47.371 & 0.009 & -0.006 & 0.07 \\
\hline Water & 536.162 & 57.812 & 0.011 & -0.007 & 0.09 \\
\hline Water & 544.441 & 70.114 & 0.012 & -0.006 & 0.12 \\
\hline Water & 552.770 & 84.526 & 0.014 & -0.001 & 0.15 \\
\hline Water & 561.143 & 101.32 & 0.02 & 0.02 & 0.20 \\
\hline Water & 569.589 & 120.78 & 0.02 & 0.00 & 0.24 \\
\hline
\end{tabular}

${ }^{a}$ IP denotes inclined piston; water or decane refers to the material used as the standard in the reference ebulliometer; $T$ is the condensation temperature of the 


\begin{abstract}
sample; the pressure $p$ for ebulliometric measurements was calculated from the condensation temperature of the reference substance; $\Delta p$ is the difference between the experimental vapor pressure and that calculated with equation 3 and the parameters listed in table $8 ; U(p)$ is the expanded uncertainty ( 0.95 level of confidence) calculated from equations 1 and 2 with coverage factor $k=2, \Delta T$ is the difference between the boiling and condensation temperatures in the ebulliometric measurements. The standard uncertainty for the measured temperatures is $u(T) / \mathrm{K}=0.002$.
\end{abstract}




\section{TABLE 8}

Parameters for the Wagner vapor pressure equation, selected critical constants, and acentric factor for 1-naphthol ${ }^{a}$

$\begin{array}{lll}\text { A } & -9.500420 & T_{\mathrm{c}}=815 \mathrm{~K}^{b} \\ \text { B } & 4.821211 & p_{\mathrm{c}}=3670 \mathrm{kPa} \\ \text { C } & -6.414380 & \rho_{\mathrm{c}}=335.0 \mathrm{~kg} \cdot \mathrm{m}^{-3} \\ \text { D } & -3.623653 & \omega=0.4746\end{array}$

a Critical parameters were estimated, as described in the text. The values for $T_{\mathrm{c}}$ and $p_{\mathrm{c}}$ are closely correlated.

$b$ The standard uncertainty for the estimated $T_{\mathrm{c}}$ is $\sim 10 \mathrm{~K}$, and the values for $T_{\mathrm{c}}$ and $p_{\mathrm{c}}$ are closely correlated. Consequently, the uncertainty in $T_{\mathrm{c}}$ makes a negligible contribution to the uncertainties for the derived properties. 


\section{TABLE 9}

Enthalpies of vaporization $\Delta_{\mathrm{l}}^{\mathrm{g}} H_{\mathrm{m}}$ for 1-naphthol derived with the fitted vapor-pressure curves and the Clapeyron equation ${ }^{a}$

\begin{tabular}{lccccc}
\hline$T / \mathrm{K}$ & $\Delta_{\mathrm{l}}^{\mathrm{g}} H_{\mathrm{m}} /\left(\mathrm{kJ} \cdot \mathrm{mol}^{-1}\right)$ & $T / \mathrm{K}$ & $\Delta_{\mathrm{l}}^{\mathrm{g}} H_{\mathrm{m}} /\left(\mathrm{kJ} \cdot \mathrm{mol}^{-1}\right)$ & $T / \mathrm{K}$ & $\Delta_{\mathrm{l}}^{\mathrm{g}} H_{\mathrm{m}} /\left(\mathrm{kJ} \cdot \mathrm{mol}^{-1}\right)$ \\
\hline $298.15^{b}$ & $74.72 \pm 0.83$ & 400.00 & $65.61 \pm 0.25$ & 520.00 & $56.30 \pm 0.30$ \\
$300.00^{b}$ & $74.54 \pm 0.80$ & 420.00 & $64.01 \pm 0.23$ & 540.00 & $54.70 \pm 0.37$ \\
$320.00^{b}$ & $72.62 \pm 0.52$ & 440.00 & $62.44 \pm 0.22$ & 560.00 & $53.06 \pm 0.48$ \\
$340.00^{b}$ & $70.76 \pm 0.38$ & 460.00 & $60.90 \pm 0.22$ & $580.00^{b}$ & $51.38 \pm 0.60$ \\
$360.00^{b}$ & $68.98 \pm 0.30$ & 480.00 & $59.38 \pm 0.22$ & $600.00^{b}$ & $49.61 \pm 0.75$ \\
380.00 & $67.26 \pm 0.27$ & 500.00 & $57.84 \pm 0.25$ & & \\
\hline
\end{tabular}

${ }^{a}$ Uncertainties are expanded uncertainties with 0.95 level of confidence.

${ }^{b}$ The value at this temperature was calculated with extrapolated vapor pressures. 


\section{TABLE 10}

Details of a typical combustion experiment for 1-naphthol at $T=298.15 \mathrm{~K}$

$\left(p^{\circ}=101.325 \mathrm{kPa}\right)^{a}$

\begin{tabular}{lc}
\hline$m^{\prime}($ compound $) / \mathrm{g}$ & 0.970008 \\
$m^{\prime \prime}($ fuse $) / \mathrm{g}$ & 0.00187 \\
$n_{\mathrm{i}}\left(\mathrm{H}_{2} \mathrm{O}\right) / \mathrm{mol}$ & 0.055345 \\
$m(\mathrm{Pt}) / \mathrm{g}$ & 19.927 \\
$\Delta T / \mathrm{K}=\left(T_{\mathrm{i}}-T_{\mathrm{f}}+\Delta T_{\text {corr }}\right) / \mathrm{K}$ & 1.98587 \\
$\varepsilon($ calor $)(\Delta T) / \mathrm{J}$ & -33334.2 \\
$\varepsilon($ cont $)(\Delta T)^{b} / \mathrm{J}$ & -36.7 \\
$\Delta U_{\text {ign }} / \mathrm{J}$ & 0.8 \\
$\Delta U(\text { corrected to standard states })^{c} / \mathrm{J}$ & 21.9 \\
$-m^{\prime \prime}\left(\Delta_{\mathrm{c}} U^{\circ} / \mathrm{M}\right)$ (fuse) / J & 20.1 \\
$m^{\prime}\left(\Delta_{\mathrm{c}} U^{\circ} / \mathrm{M}\right)$ (compound) / J & -33328.1 \\
$\left(\Delta_{\mathrm{c}} U^{\circ} / \mathrm{M}\right)($ compound $) /\left(\mathrm{J} \cdot \mathrm{g}^{-1}\right)$ & -34358.6 \\
\end{tabular}

${ }^{a}$ The symbols and abbreviations of this table are those of reference 24, except as noted.

${ }^{b} \varepsilon_{\mathrm{i}}($ cont $)\left(T_{\mathrm{i}}-298.15 \mathrm{~K}\right)+\varepsilon_{\mathrm{f}}($ cont $)\left(298.15 \mathrm{~K}-T_{\mathrm{f}}+\Delta T_{\text {corr }}\right)$

${ }^{c}$ Items 81 to 85,87 to 90,93 , and 94 of the computational form of reference 24 . 


\section{TABLE 11}

Summary of experimental energy of combustion results and molar thermodynamic functions at $T=298.15 \mathrm{~K}$ and $p^{\circ}=101.325 \mathrm{kPa}$ for 1 -naphthol

\begin{tabular}{|c|c|c|c|c|c|}
\hline $\multicolumn{6}{|c|}{\left(\Delta_{\mathrm{c}} U^{\circ} / \mathrm{M}\right)(1-$ naphthol, cr $)} /\left(\mathrm{J} \cdot \mathrm{g}^{-1}\right)$ \\
\hline-34359.0 & -34356.7 & -34354.5 & -34359.4 & -34358.6 & -34358.1 \\
\hline \multicolumn{4}{|c|}{$<\left\{\left(\Delta_{\mathrm{c}} U^{\circ} / \mathrm{M}\right)(1-\right.$ naphthol, cr $\left.\left.)\right\} /\left(\mathrm{J} \cdot \mathrm{g}^{-1}\right)\right\rangle$} & \multicolumn{2}{|c|}{$-34357.7 \pm 0.7^{b}$} \\
\hline \multicolumn{4}{|c|}{$\Delta_{\mathrm{c}} U_{\mathrm{m}}^{\mathrm{o}}(1-$ naphthol, $\mathrm{cr}) /\left(\mathrm{kJ} \cdot \mathrm{mol}^{-1}\right)$} & \multicolumn{2}{|c|}{$-4953.5 \pm 0.7^{b}$} \\
\hline \multicolumn{4}{|c|}{$\Delta_{\mathrm{c}} H_{\mathrm{m}}^{\mathrm{o}}(1-$ naphthol, $\mathrm{cr}) /\left(\mathrm{kJ} \cdot \mathrm{mol}^{-1}\right)$} & \multicolumn{2}{|c|}{$-4957.2 \pm 0.7^{b}$} \\
\hline \multicolumn{4}{|c|}{$\Delta_{\mathrm{f}} H_{\mathrm{m}}^{\mathrm{o}}(1-$ naphthol, $\mathrm{cr}) /\left(\mathrm{kJ} \cdot \mathrm{mol}^{-1}\right)$} & \multicolumn{2}{|c|}{$-121.2 \pm 1.5^{c}$} \\
\hline
\end{tabular}

$a$ Uncertainties for all values are the "uncertainty interval" as defined in reference 38. These values are equivalent to the combined expanded uncertainty with 0.95 level of confidence.

$b$ Value for the idealized combustion reaction:

$$
\mathrm{C}_{10} \mathrm{H}_{8} \mathrm{O}(\mathrm{cr})+11.5 \mathrm{O}_{2}(\mathrm{~g})=10 \mathrm{CO}_{2}(\mathrm{~g})+4 \mathrm{H}_{2} \mathrm{O}(\mathrm{l}) \text {. }
$$

$c$ Value for the formation reaction:

$$
10 \mathrm{C}(\mathrm{cr} \text {, graphite })+4 \mathrm{H}_{2}(\mathrm{~g})+0.5 \mathrm{O}_{2}(\mathrm{~g})=\mathrm{C}_{10} \mathrm{H}_{8} \mathrm{O}(\mathrm{cr}) \text {. }
$$


TABLE 12

Molar thermodynamic properties for 1-naphthol in the ideal gas state at $\mathrm{p}=\mathrm{p}^{\circ}=101.325 \mathrm{kPa}$ $\left(R=8.3144621 \mathrm{~J} \cdot \mathrm{K}^{-1} \cdot \mathrm{mol}^{-1}\right)^{a}$

\begin{tabular}{llllllll}
\hline$T / \mathrm{K}$ & $\Delta_{0}^{T} H_{\mathrm{m}}^{\mathrm{o}} / R T$ & $\Delta_{\mathrm{imp}} H_{\mathrm{m}} / R T^{b}$ & $\Delta_{0}^{T} S_{\mathrm{m}}^{\mathrm{o}} / R$ & $\Delta_{\mathrm{imp}} S_{\mathrm{m}} / R^{c}$ & $\Delta_{\mathrm{f}} H_{\mathrm{m}}^{\mathrm{o}} / R T$ & $\Delta_{\mathrm{f}} S_{\mathrm{m}}^{\mathrm{o}} / R$ & $\Delta_{\mathrm{f}} G_{\mathrm{m}}^{\mathrm{o}} / R T$ \\
\hline $298.15^{d e}$ & $48.40 \pm 0.34$ & 0.00 & $44.92 \pm 0.34$ & 0.00 & $-11.08 \pm 0.46$ & $-37.13 \pm 0.34$ & $26.05 \pm 0.32$ \\
$300.00^{d e}$ & $48.22 \pm 0.32$ & 0.00 & $45.04 \pm 0.32$ & 0.00 & $-11.05 \pm 0.46$ & $-37.17 \pm 0.32$ & $26.12 \pm 0.32$ \\
$320.00^{d e}$ & $46.46 \pm 0.20$ & 0.00 & $46.33 \pm 0.20$ & 0.00 & $-10.76 \pm 0.36$ & $-37.59 \pm 0.20$ & $26.83 \pm 0.30$ \\
$340.00^{d e}$ & $44.96 \pm 0.14$ & 0.00 & $47.60 \pm 0.14$ & 0.00 & $-10.50 \pm 0.32$ & $-37.97 \pm 0.14$ & $27.47 \pm 0.30$ \\
$360.00^{d e}$ & $43.70 \pm 0.10$ & 0.00 & $48.87 \pm 0.12$ & 0.00 & $-10.24 \pm 0.28$ & $-38.30 \pm 0.12$ & $28.06 \pm 0.28$ \\
$380.00^{e}$ & $42.63 \pm 0.10$ & 0.00 & $50.13 \pm 0.12$ & 0.00 & $-9.99 \pm 0.26$ & $-38.61 \pm 0.12$ & $28.61 \pm 0.26$ \\
$400.00^{d}$ & $41.72 \pm 0.08$ & 0.00 & $51.38 \pm 0.10$ & 0.00 & $-9.76 \pm 0.26$ & $-38.88 \pm 0.10$ & $29.12 \pm 0.26$ \\
$420.00^{d}$ & $40.94 \pm 0.08$ & 0.01 & $52.62 \pm 0.10$ & 0.01 & $-9.53 \pm 0.24$ & $-39.12 \pm 0.10$ & $29.59 \pm 0.24$ \\
$440.00^{e}$ & $40.29 \pm 0.08$ & 0.02 & $53.86 \pm 0.10$ & 0.01 & $-9.31 \pm 0.22$ & $-39.33 \pm 0.10$ & $30.03 \pm 0.24$ \\
$460.00^{e}$ & $39.73 \pm 0.08$ & 0.03 & $55.08 \pm 0.10$ & 0.02 & $-9.10 \pm 0.22$ & $-39.53 \pm 0.10$ & $30.44 \pm 0.22$ \\
$480.00^{e}$ & $39.25 \pm 0.08$ & 0.04 & $56.28 \pm 0.10$ & 0.03 & $-8.89 \pm 0.22$ & $-39.71 \pm 0.10$ & $30.82 \pm 0.22$ \\
$500.00^{e}$ & $38.85 \pm 0.08$ & 0.06 & $57.48 \pm 0.10$ & 0.04 & $-8.70 \pm 0.20$ & $-39.87 \pm 0.10$ & $31.18 \pm 0.22$ \\
$520.00^{e}$ & $38.51 \pm 0.10$ & 0.08 & $58.65 \pm 0.12$ & 0.06 & $-8.51 \pm 0.20$ & $-40.03 \pm 0.12$ & $31.52 \pm 0.22$ \\
$540.00^{e}$ & $38.22 \pm 0.12$ & 0.12 & $59.81 \pm 0.14$ & 0.09 & $-8.34 \pm 0.20$ & $-40.17 \pm 0.14$ & $31.83 \pm 0.22$ \\
$560.00^{e}$ & $37.98 \pm 0.14$ & 0.16 & $60.96 \pm 0.16$ & 0.12 & $-8.16 \pm 0.22$ & $-40.29 \pm 0.16$ & $32.13 \pm 0.24$ \\
$580.00^{e}$ & $37.78 \pm 0.18$ & 0.21 & $62.09 \pm 0.20$ & 0.16 & $-8.00 \pm 0.24$ & $-40.41 \pm 0.20$ & $32.41 \pm 0.26$ \\
$600.00^{e}$ & $37.62 \pm 0.22$ & 0.27 & $63.20 \pm 0.24$ & 0.20 & $-7.84 \pm 0.26$ & $-40.51 \pm 0.24$ & $32.68 \pm 0.28$
\end{tabular}

${ }^{a}$ Uncertainties are the expanded uncertainty at 0.95 level of confidence.

${ }^{b}$ Gas-imperfection correction included in the molar enthalpy for the ideal gas (column 2). The molar enthalpy of the gas is calculated relative to that of the crystals at $T \rightarrow 0$.

${ }^{c}$ Gas-imperfection correction included in the molar entropy for the ideal gas (column 4).

${ }^{d}$ Values at this temperature were calculated with extrapolated vapor pressures calculated from the fitted parameters (table 8) of the Wagner equation \{eq. (3)\}.

${ }^{e}$ Values at this temperature were calculated with extrapolated heat capacity values for the liquid phase. 
TABLE 13.

Rotational constants, A, B, and C for 1-naphthol conformations. ${ }^{a}$

\begin{tabular}{|c|c|c|c|c|}
\hline & "trans" & & “cis" & \\
\hline & computed $^{b}$ & experiment $^{c}$ & computed $^{b}$ & experiment ${ }^{c}$ \\
\hline$A$ & 1.9362 & 1.9421 & 1.9426 & 1.9476 \\
\hline$B$ & 1.1278 & 1.1336 & 1.1174 & 1.1243 \\
\hline$C$ & 0.7127 & 0.7160 & 0.7094 & 0.7131 \\
\hline geometric mean & 1.1589 & 1.1638 & 1.1548 & 1.1601 \\
\hline
\end{tabular}

${ }^{a}$ All values are expressed in GHz.

b Computed at the B3LYP/6-31+G(d,p) level of theory, as describe in the text.

${ }^{c}$ From Johnson et al. [42]. 
TABLE 14

Calculated fundamental vibrational wavenumbers $\bar{v}$ used in the computation of the idealgas entropies for the "cis" and "trans" conformers of 1-naphthol ${ }^{a}$

\begin{tabular}{ccccc}
\hline $\bar{v} / \mathrm{cm}^{-1}$ & $\bar{v} / \mathrm{cm}^{-1}$ & $\bar{v} / \mathrm{cm}^{-1}$ & $\bar{v} / \mathrm{cm}^{-1}$ & $\bar{v} / \mathrm{cm}^{-1}$ \\
\hline "cis" configuration & & & & \\
$60.1^{b}$ & 568.0 & 928.6 & 1213.2 & 1606.4 \\
168.8 & 609.8 & 951.9 & 1255.3 & 1637.6 \\
186.9 & 704.0 & 967.8 & 1274.2 & 3075.9 \\
256.2 & 711.8 & 1016.1 & 1364.3 & 3098.7 \\
289.7 & 746.1 & 1035.7 & 1378.4 & 3103.8 \\
413.1 & 774.6 & 1078.3 & 1400.2 & 3112.9 \\
455.2 & 778.2 & 1141.9 & 1447.4 & 3118.9 \\
461.2 & 834.3 & 1151.5 & 1461.4 & 3126.0 \\
470.0 & 863.5 & 1163.1 & 1519.1 & 3133.0 \\
517.7 & 872.2 & 1173.9 & 1583.5 & 3751.7 \\
561.4 & & & & \\
"trans" configuration & & & & \\
$329.5{ }^{b}$ & 569.3 & 941.0 & 1222.0 & 1603.1 \\
136.8 & 618.8 & 952.7 & 1239.7 & 1635.9 \\
171.7 & 704.3 & 974.8 & 1271.9 & 3087.1 \\
255.0 & 719.3 & 1015.6 & 1363.7 & 3096.0 \\
276.6 & 759.3 & 1036.1 & 1384.0 & 3104.4 \\
419.5 & 776.4 & 1075.8 & 1398.6 & 3108.0 \\
456.7 & 778.9 & 1136.7 & 1452.8 & 3120.5 \\
464.1 & 839.5 & 1146.0 & 1462.0 & 3122.2 \\
473.3 & 863.3 & 1158.8 & 1519.0 & 3141.0 \\
518.1 & 865.4 & 1187.1 & 1583.6 & 3734.5 \\
567.6 & & & & \\
Energy levels for the OH torsion & $c$ & & & \\
160.2 & 817.6 & 1221.7 & 1589.6 & 2161.3 \\
471.0 & 1012.5 & 1376.0 & 1849.4 & 2518.8 \\
620.6 & 1024.5 & 1389.0 & 1850.1 & 2518.8 \\
757.8 & 1208.9 & 1585.2 & 2161.3 & 2921.0 \\
\hline & & & & \\
\hline
\end{tabular}

The scale factor 0.975 has been applied to all wavenumber values.

$b$ This frequency is associated with the $\mathrm{OH}$ torsion, which was modeled separately, as described in the text.

$c$ The first 20 energy levels obtained from numerical solution of the one-dimensional Schrödinger equation for the $\mathrm{OH}$ torsion, as described in the text. Higher energy levels do not contribute significantly to the thermodynamic properties considered here. 


\section{TABLE 15}

Comparison of enthalpies of fusion reported in the literature for 1-naphthol with that of this research ${ }^{a}$

\begin{tabular}{clcr}
\hline Reference Number & Literature Source (Year) & $\Delta_{\mathrm{l}}^{\mathrm{g}} H_{\mathrm{m}} /\left(\mathrm{kJ} \cdot \mathrm{mol}^{-1}\right)$ & Deviation ${ }^{b}$ \\
\hline- & This research & $(24.26 \pm 0.02)$ & \\
50 & Gupta et al. (2012) & 21.62 & -11 \\
51 & Rai and Rai (1998) & 24.40 & 1 \\
52 & Sharma et al. (1992) & 23.93 & -1 \\
53 & Rai and George (1992) & 22.71 & -6 \\
54 & Mandal (1992) & 23.47 & -3 \\
55 & Rai and Mandal (1990) & 23.47 & -3 \\
56 & Donnelly et al. (1990) & 22.33 & -8 \\
57 & Rai et al. (1989) & 22.80 & -6 \\
58 & Singh et al. (1985) & 23.49 & -3 \\
59 & Khetarpal et al. (1979) & 23.33 & -4 \\
60 & Singh et al. (1978) & 23.30 & -4 \\
61 & Singh and Singh (1975) & 23.28 & -4 \\
62 & Pacor (1967) & 23.22 & -3 \\
63 & Andrews et al. (1926) & 23.47 & \\
\end{tabular}

a Claimed relative uncertainties for the literature values were all near 1 percent.

$b$ The relative deviation of the literature value from that of this research expressed as $100\left\{\Delta_{\mathrm{l}}^{\mathrm{g}} H_{\mathrm{m}}(\right.$ literature $)-\Delta_{\mathrm{l}}^{\mathrm{g}} H_{\mathrm{m}}($ this research $\left.)\right\} / \Delta_{\mathrm{l}}^{\mathrm{g}} H_{\mathrm{m}}($ this research $)$. 


\section{TABLE 16}

Comparison of enthalpies of combustion for 1-naphthol reported in the literature with that of this research ${ }^{a}$

\begin{tabular}{cll} 
Reference Number & Literature Source (Year) & $-\Delta_{\mathrm{c}} H_{\mathrm{m}}^{\mathrm{o}}(\mathrm{cr}) /\left(\mathrm{kJ} \cdot \mathrm{mol}^{-1}\right)^{\mathrm{a}}$ \\
\hline- & This research & $(4957.2 \pm 0.7)$ \\
77 & Balcan et al. (1996) & $(4951.1 \pm 4.9)$ \\
76 & Ribeiro da Silva et al. (1988) & $(4956.4 \pm 0.8)$ \\
72 & Colomina et al. (1974) & $(4957.4 \pm 0.9)$ \\
75 & Leman and Lepoutre (1946) & $(4965.6 \pm 2.1)$
\end{tabular}

a Uncertainties are those reported in the original source. 


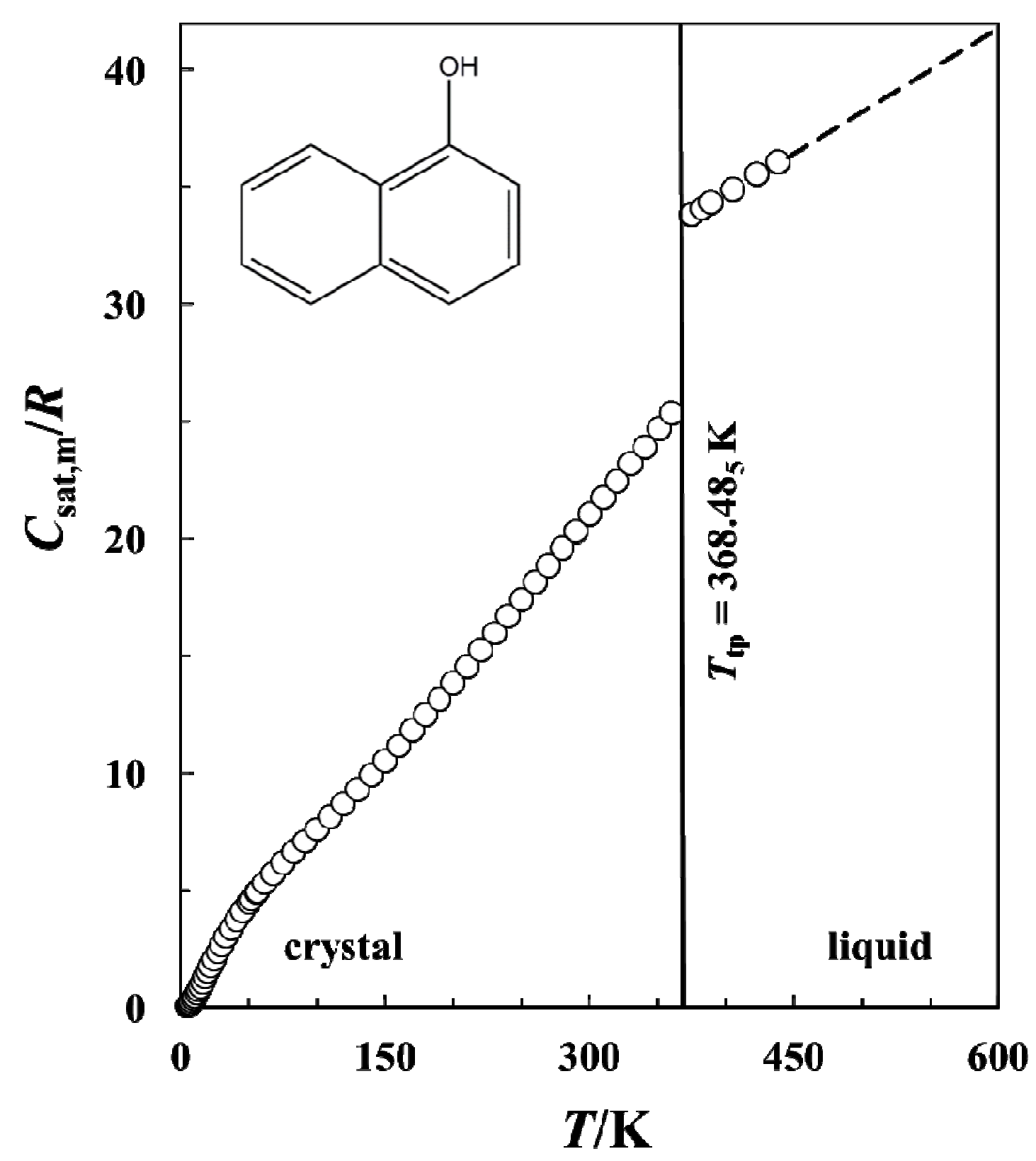

FIGURE 1. Plot of molar heat capacities against temperature at saturation pressure $C_{\mathrm{sat}, \mathrm{m}}$ for 1-naphthol measured in this research. The vertical line indicates the triple-point temperature $T_{\mathrm{tp}}$, and the dashed line represents extrapolated heat capacities for the liquid phase. $\bigcirc$, Experimental values determined with adiabatic calorimetry in this research and corrected for pre-melting near $T_{\mathrm{tp}}$. 


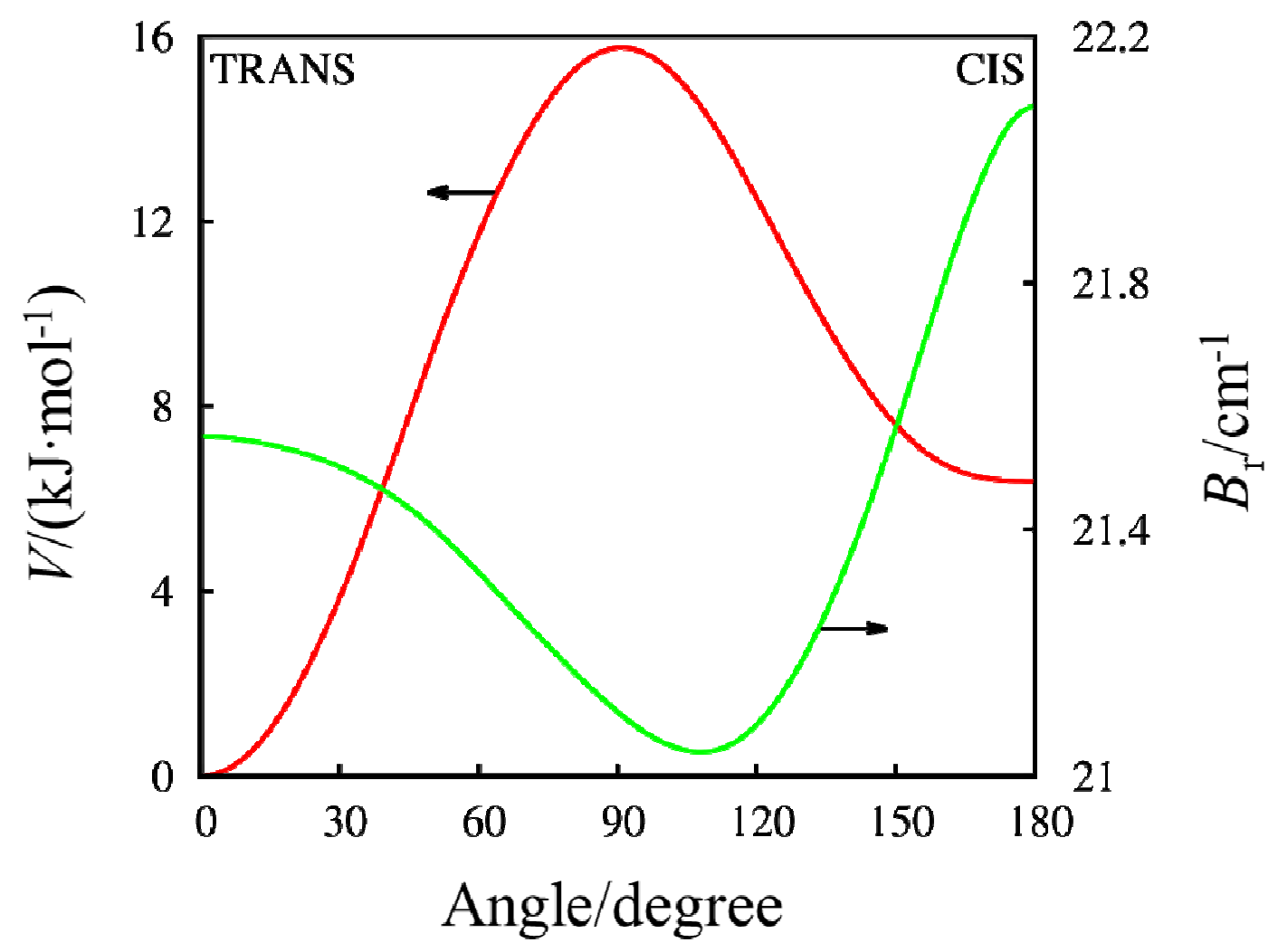

FIGURE 2. Rotational potential $V$ and reduced rotational constant $B_{\mathrm{r}}$ as a function of the angle of rotation computed at B3LYP/6-31+G(d,p) level. The portion from $180^{\circ}$ to $360^{\circ}$ is the mirror image of that shown. The arrows indicate the vertical axis associated with each curve. 


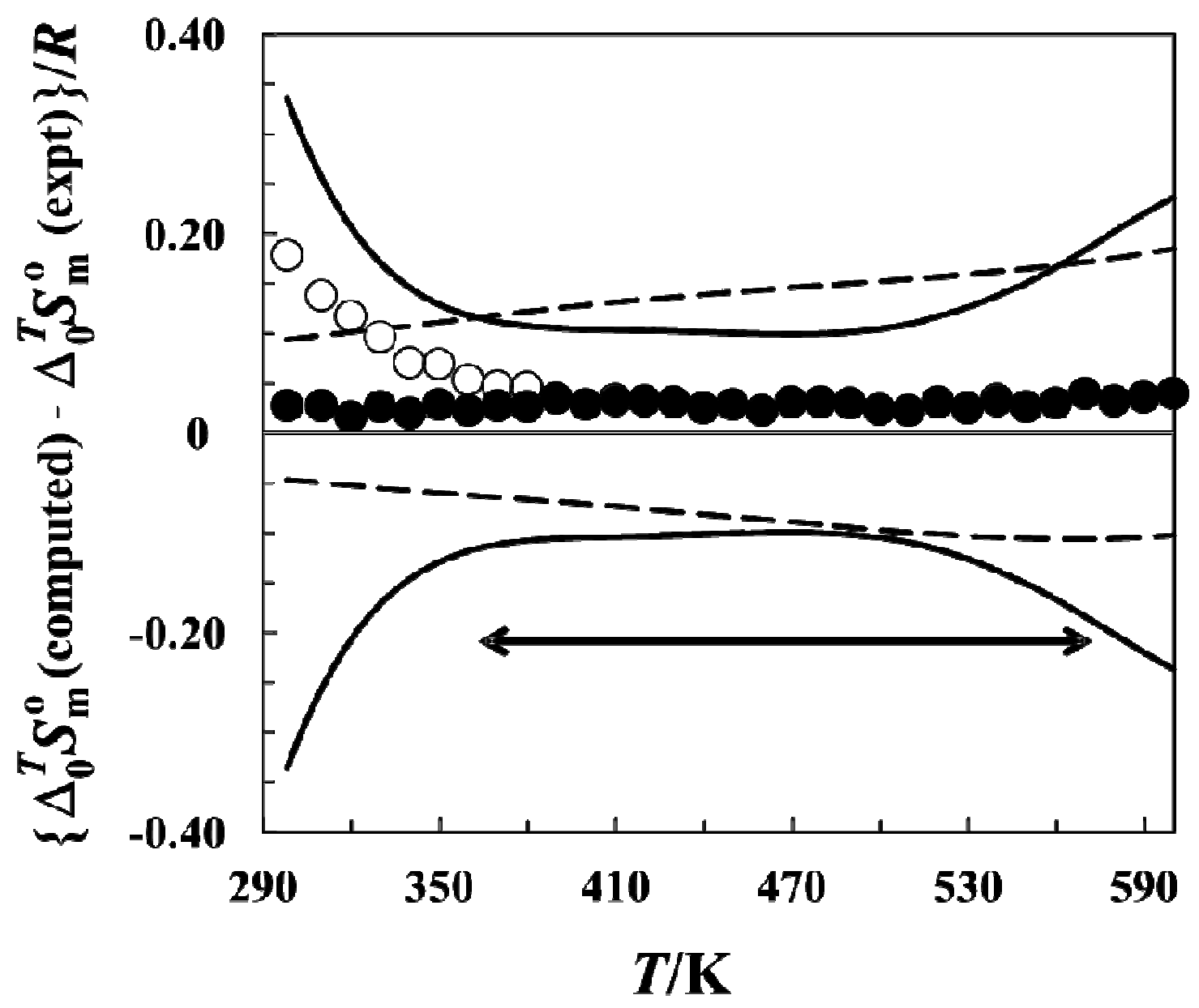

FIGURE 3. Difference plot for ideal-gas entropies $\Delta_{0}^{T} S_{\mathrm{m}}^{\mathrm{o}}$ against temperature for 1naphthol derived with computed vibrational frequencies (table 13) and the methods described in the text $\Delta_{0}^{T} S_{\mathrm{m}}^{\mathrm{o}}$ (computed) and those derived from the experimental thermodynamic property measurements $\Delta_{0}^{T} S_{\mathrm{m}}^{\mathrm{o}}(\operatorname{expt}) . \Delta_{0}^{T} S_{\mathrm{m}}^{\mathrm{o}}(\operatorname{expt})$ was calculated with two forms of the Wagner equation (described in the text). $\bullet, 2.5 / 6 ; \bigcirc, 2.5 / 5 ; \square$. The continuous curved lines represent the expanded uncertainties for $\Delta_{0}^{T} S_{\mathrm{m}}^{\mathrm{o}}$ (expt). The dashed lines represent differences between $\Delta_{0}^{T} S_{\mathrm{m}}^{\mathrm{o}}(\operatorname{expt})$, calculated with the 2.5/6 form of the Wagner equation and $\Delta_{0}^{T} S_{\mathrm{m}}^{\mathrm{o}}$ (computed) derived with scale factors $F=0.970$ (upper dashed curve) and $F=0.980$ (lower dashed curve). The double-headed arrow indicates the range of the vapor pressures measured in this research (table 7). 


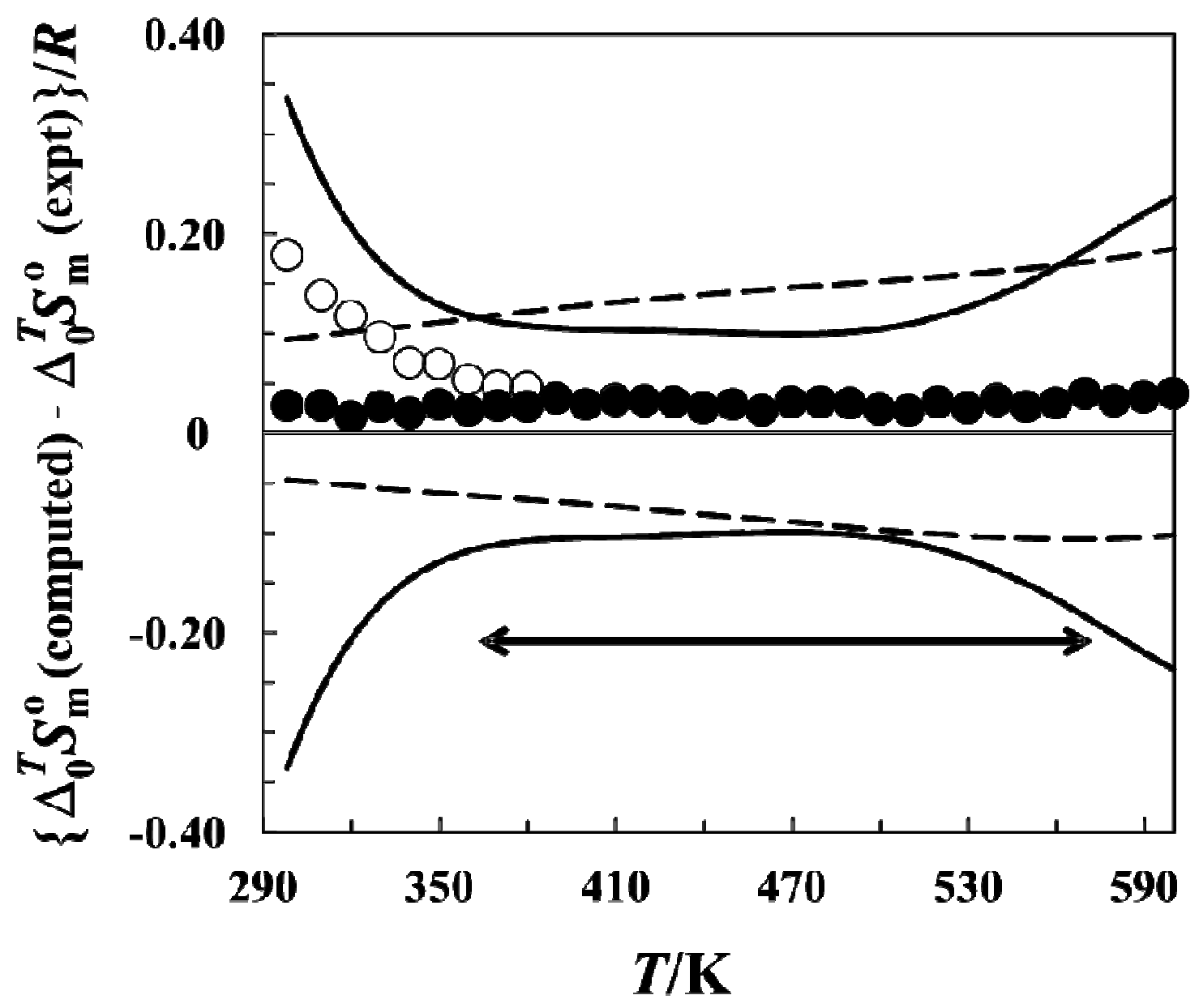

FIGURE 3. Difference plot for ideal-gas entropies $\Delta_{0}^{T} S_{\mathrm{m}}^{\mathrm{o}}$ against temperature for 1naphthol derived with computed vibrational frequencies (table 13) and the methods described in the text $\Delta_{0}^{T} S_{\mathrm{m}}^{\mathrm{o}}$ (computed) and those derived from the experimental thermodynamic property measurements $\Delta_{0}^{T} S_{\mathrm{m}}^{\mathrm{o}}(\operatorname{expt}) . \Delta_{0}^{T} S_{\mathrm{m}}^{\mathrm{o}}(\operatorname{expt})$ was calculated with two forms of the Wagner equation (described in the text). $\bullet, 2.5 / 6 ; \bigcirc, 2.5 / 5 ; \square$. The continuous curved lines represent the expanded uncertainties for $\Delta_{0}^{T} S_{\mathrm{m}}^{\mathrm{o}}$ (expt). The dashed lines represent differences between $\Delta_{0}^{T} S_{\mathrm{m}}^{\mathrm{o}}(\operatorname{expt})$, calculated with the 2.5/6 form of the Wagner equation and $\Delta_{0}^{T} S_{\mathrm{m}}^{\mathrm{o}}$ (computed) derived with scale factors $F=0.970$ (upper dashed curve) and $F=0.980$ (lower dashed curve). The double-headed arrow indicates the range of the vapor pressures measured in this research (table 7). 


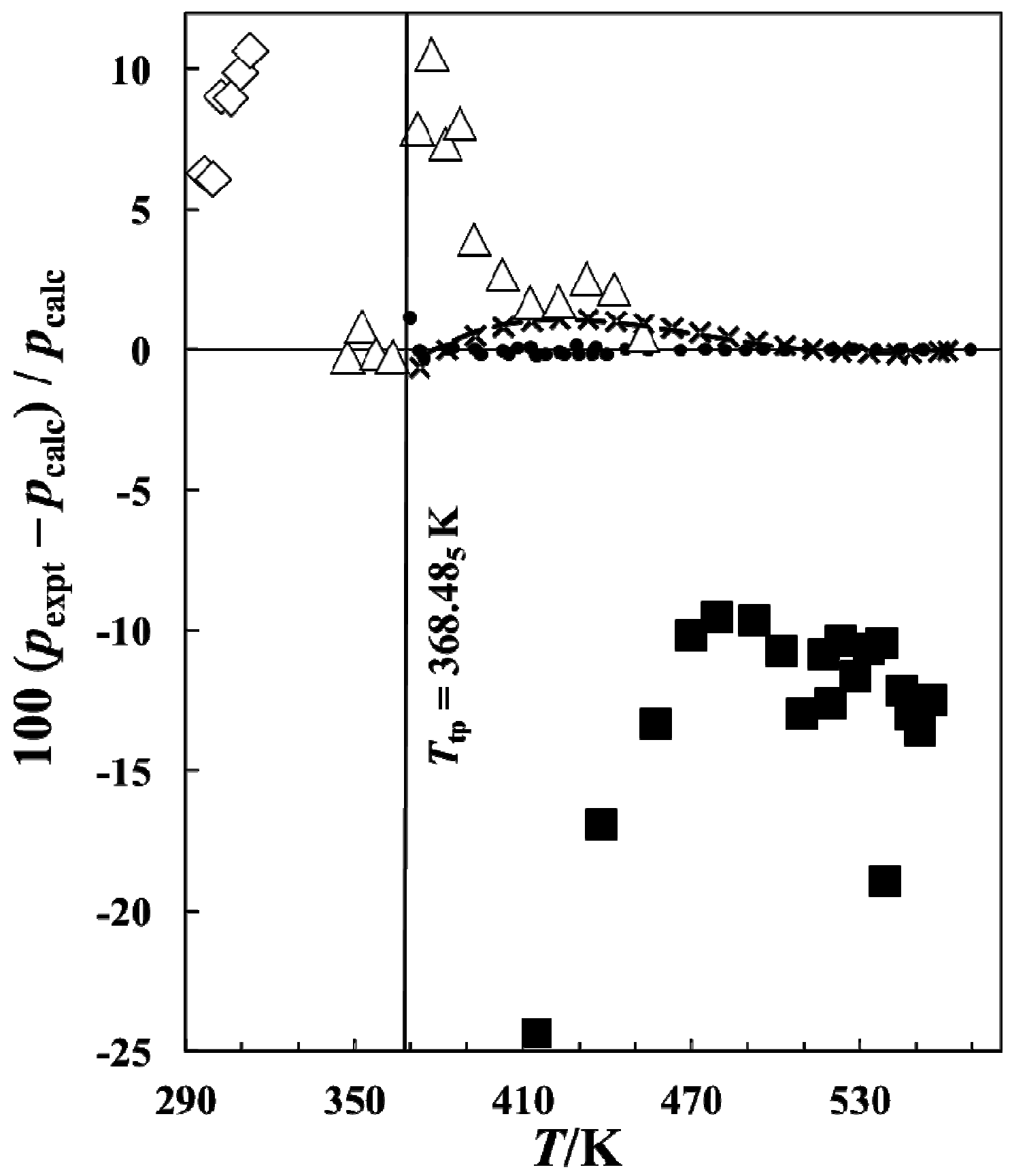

FIGURE 4. Deviation plot for experimental vapor and sublimation pressures for 1naphthol relative to the fitted equations of this research for vapor pressure \{ equation (3) and the parameters of table 8$\}$ and sublimation pressure \{equation (8)\}. $\Delta$, Sakoguchi, et al. [70]; $\diamond$, Colomina, et al. [72]; $\mathbf{-}$, Terres, et al. [69]; *, May et al. [68]; •, this research. The vertical line indicates the triple-point temperature $T_{\mathrm{tp}}$ for 1-naphthol. 